\title{
Soldados y urnas. Análisis de las causas históricas de la supresión del voto militar en Colombia ${ }^{1}$
}

\author{
https://doi.org/10.21830/9789585318380.06
}

\author{
Oscar José Pérez Deaquiz² \\ Escuela Militar de Cadetes "General José María Córdova”
}

\section{Resumen}

El presente texto presenta un estudio documental que permite comprender la relación entre el estatus de ciudadano, su correspondencia con el derecho a sufragar y su relación con la profesión militar en Colombia. Exhibe la interrelación de causas que generaron la pérdida del voto para el personal militar activo en el país, quienes gozaron del derecho a sufragar por 120 años, desde 1810 hasta 1930, asimismo, presenta los hechos que motivaron esta determinación. Todo lo ello, por medio de un estudio historiográfico de tipo genético que analiza el hecho histórico y su contexto, enfocado en las relaciones de poder.

Palabras clave: ciudadanía; Constitución; militar; sufragio; supresión; vecino.

\section{Introducción}

Los miembros de las Fuerzas Militares de Colombia gozaron del derecho al voto hasta el año de 1930, cuando el Congreso de la República sancionó la Ley ordinaria No. 72 (Congreso de la República, 1930), en la cual, en desarrollo del artículo 168 de la Constitución Política de 1886, se les prohibió ejercer la función de sufragio mientras permanecieran en servicio activo. En la actualidad, según los datos reportados para el año 2017 por el Banco Mundial,

1 Este capítulo hace parte de los resultados del proyecto de investigación "Relaciones civiles-militares en Colombia: una aproximación a los roles de las Fuerzas Militares" del Grupo de Investigación en Ciencias Militares de la Escuela Militar de Cadetes "General José María Córdova" categorizado en B por Minciencias y con código de registro COL0082556. Los puntos de vista y los resultados de este artículo pertenecen al autor y no reflejan necesariamente los de las instituciones participantes.

2 Mayor del Ejército Nacional de Colombia. Magíster en Liderazgo Democrático y Comunicación Política (Universidad Complutense de Madrid). Magíster en Historia Militar (Escuela Militar de Cadetes “General José María Córdova). ORCID: https://orcid.org/0000-0002-9958-6069 - Contacto: oscar.perez@ esmic.edu.co 
el personal activo de las Fuerzas Armadas de Colombia es de 481.000 uniformados (militares y policías) (Banco Mundial, 2020.), colombianos a quienes la Constitución actual les prohíbe votar.

En el transcurso de los diferentes periodos constitucionales de Colombia ${ }^{3}$, los militares gozaron del derecho al sufragio, considerado como un privilegio excluyente que facultaba su ejercicio solo a ciudadanos que cumplieran con tres factores: 1) factores sociales (de utilidad, autonomía y capacidad); 2) factores económicos (pago de impuestos y capacidad adquisitiva); y 3) factores políticos (leyes, nacionalidad, edad, género, entre otros).

A lo largo de los siglos XIX y XX, se presentaron diferentes cambios constitucionales en las restricciones del sufragio, sin embargo, en la actualidad no se identifican con claridad cuáles fueron las razones históricas que motivaron a prescindir del derecho al sufragio a los miembros activos de Fuerzas Militares en Colombia. La idea de la presente investigación se enmarca en las ciencias sociales, específicamente en la ciencia política, las ciencias militares y la historia militar. Analiza la transformación y participación de las Fuerzas Militares en la historia de la democracia colombiana, a la luz de los conceptos de ciudadanía (Heater, 2007), derechos políticos y Fuerzas Armadas.

Por lo anterior, "Soldados y urnas: análisis de las causas históricas de la supresión del voto militar en Colombia”, es una investigación cualitativa, de tipo hermenéutico-histórico, basada en el análisis documental de fuentes primarias y secundarias. Tiene como punto de partida el año de 1930, cuando se presenta el hecho histórico de la supresión del voto militar, y rastrea en la historia de Colombia, hasta el año de 1810, los hechos que motivaron tomar tal decisión. Se trata, entonces, de un estudio de tipo genético que analiza el hecho histórico y su contexto, haciendo énfasis en las relaciones de poder ${ }^{4}$.

El propósito del presente capítulo es presentar un análisis documental que permita comprender la relación entre el estatus de ciudadano, su correspondencia con el derecho a sufragar y su relación con la profesión militar; de

3 La República de Colombia fue antecedida por seis periodos constitucionales así: 1. Periodo de la independencia (1810-1819); 2. Periodo de la Gran Colombia (1819-1830); 3. Periodo de la Nueva Granada (1831-1858); 4. Periodo de la Confederación Granadina (1858-1860); 5. Periodo de los Estados Unidos de Colombia (1861-1886); y 6. Periodo de la República de Colombia (1886-1991-actualidad).

4 El materialismo histórico (método marxista) busca comprender las relaciones de poder, planteando que la historia no depende de las personas, sino de las relaciones de poder. 
igual manera, busca comprender la interrelación de causas que generaron la pérdida del voto para el personal militar.

Si bien en la actualidad existe información que permite abordar el tema de la evolución del sufragio en Colombia, resulta evidente la ausencia de estudios basados en las relaciones de poder en este periodo. Cabe anotar que en la actualidad el tema es de gran importancia para los estudios políticos y militares del país, ya que en los últimos años ha cobrado vigencia en los debates del Congreso de la República de Colombia (El Tiempo, 2019).

\section{El ciudadano en Colombia}

Etimológicamente, la palabra "ciudadano" posee raíces latinas que lo identifican como perteneciente a la ciudad (Etimologías de Chile, 2020.). La Real Academia Española la define como: "natural o vecino de una ciudad, perteneciente o relativo a la ciudad o a los ciudadanos, persona considerada como miembro activo de un Estado, titular de derechos políticos y sometido a sus leyes" (RAE, 2020).

Durante la primera mitad del siglo XIX en Colombia, los conceptos de "vecino" y "vecindad", permitieron enlazar las características del ciudadano (abstracto, individual, igualitario y universal) (Estrada, 2011, p. 300), producto de las revoluciones liberales —en especial la francesa-, con el proceso de adaptación del concepto de ciudadanía en Colombia. Estas nociones permitieron definir la ciudadanía en términos territoriales y culturales, asociados a un nivel político administrativo local.

Al término de las guerras de la independencia de Colombia, se presentaron grandes retos para los precursores de esta: crear un Estado; definir un orden político y jurídico; delimitar territorios; homogeneizar las leyes, la educación y el servicio de la defensa; recaudar y administrar recursos; definir conceptos como el de nación; determinar símbolos, historias comunes y sentimientos generales; incrementar la lealtad de sus habitantes; y evitar una reconquista. A todo lo anterior se sumaba la urgente necesidad de "definir la situación de los habitantes del territorio, como sujetos portadores de derechos, ya que serían ellos los que otorgarían la legitimidad del nuevo orden constitucional" (Estrada, 2011, p. 67). 
Por lo tanto, era necesario definir quiénes serían los representantes y los representados, para ello, se definieron dos tipos de ciudadanía: una civil, cuya connotación era universal y se adquiría solo por el hecho de ser nacional; y una política, cuya connotación era limitada, se adquiría cumpliendo requisitos de edad, sexo, residencia y condición económica, otorgaba al ciudadano el "derecho a votar, elegir y ser elegido, ser miembro de las instituciones militares, participar y tomar parte de la prensa política, formar organizaciones políticas, a integrar los tribunales como jurados y jueces y dirigir reclamos y peticiones al gobierno" (Estrada, 2011, p. 67). En este contexto histórico, la ciudadanía era excluyente, asociada a un sector reducido de la sociedad.

Lo anterior representa un punto de partida antagónico, frente a un proceso de independencia cuyas banderas fueron la igualdad, la libertad y los derechos. Existía una pequeña franja de poder — “hombres, mayores de edad, residentes y con patrimonio" (Estrada, 2011, p. 300)— conformada por "hacendados, terratenientes, comerciantes, sacerdotes, abogados, militares y artesanos" (Estrada, 2011, p. 68), los cuales eran considerados "vecinos libres" o ciudadanos activos, quienes habían generado un régimen de dominación sobre el resto de la población granadina. "La palabra preferida para expresar esa calidad privilegiada y corporativa del hombre de ciudad era la de vecino" (Sabato, 1999). De hecho, durante la primera mitad del siglo XIX, el "ciudadano colombiano fue siempre un hombre concreto, soportado en su calidad de vecino y adscrito a una localidad o ente físico y territorial llamado ciudad, villa, parroquia o pueblo" (Estrada, 2011, p. 302).

La carencia de poder infraestructural ${ }^{5}$ del incipiente Estado, no permitió llevar a cabo un proceso eficaz de nacionalización, por consiguiente, se presentaron graves inconvenientes a la hora de centralizar la administración, no se podía realizar un censo para la recaudación de impuestos, se tenía un extenso territorio dotado con precarias vías de comunicación, así que existían regiones aisladas que formaron identidades colectivas rivales, las cuales fueron generando disputas entre sí.

5 La Nueva Granada presentaba una profunda fragmentación en algunas regiones del territorio nacional, lo que se intensificaba por la accidentada geografía del territorio, que condenaba al aislamiento a diferentes comarcas, situación que empeoraba por la pobrísima infraestructura en vías de comunicación (Estrada, 2011, p. 300). 
El fallido proceso de centralización otorgó un poder indirecto a las administraciones locales, las cuales se encargaron de conceder los nuevos derechos políticos. De este modo, el concepto de "vecino" se convierte en un articulador de la sociedad, encontrándose "asociado al territorio de pertenencia y con una precisa adscripción espacial: la localidad” (Estrada, 2011, p. 72).

El término "vecindad" pasa a relacionarse directamente con la ciudadanía; cada administración contaba con su respectiva parroquia, la cual se desempeñaba como estamento articulador de la sociedad tradicional "condicionando la vida administrativa y política de los vecinos" (Estrada, 2011, p. 72). La condición de "vecino" estaba jerarquizada en tres tipos de vecindad: la parroquial, la provincial y la distrital. Da tal modo que cada persona obtenía tres tipos de vecindades; simultáneamente adquiría diferentes obligaciones y derechos. Por ejemplo, si la persona cambiaba de distrito perdía la vecindad adquirida y debía solicitar otra; además, si un varón perdía sus derechos como vecino de igual manera los perdía su esposa.

\section{Historiografía de la ciudadanía activa y el sufragio militar}

El contexto histórico del momento nos ubica en el primer cuarto del siglo XIX, en el ámbito internacional (ver figura 1), el mundo se encuentra en plena Revolución Industrial (1760-1840), y la Revolución francesa (17891799) acaba de culminar. Las ideas liberales traídas de Europa, sumadas a los recuerdos de las insurrecciones contra la Corona española, los motines contra los impuestos del tercer y último cuarto del siglo XVIII, las revoluciones hispanoamericanas — Revolución de los Comuneros de 1781 en la Nueva Granada, y las revueltas de Túpac Amaru en el Perú (Bushnell, 2014, p. 54)—, la profunda crisis de la monarquía española por la captura de la familia real y la pérdida del trono de Fernando VII a manos de Napoleón, así como el inconformismo de los criollos ${ }^{6}$ por no poder gobernar las colonias en América, generó que se pusiera en marcha y estallara el movimiento independentista en Colombia (Bushnell, 2014, p. 63).

6 Persona nacida en América cuyos padres eran europeos. 


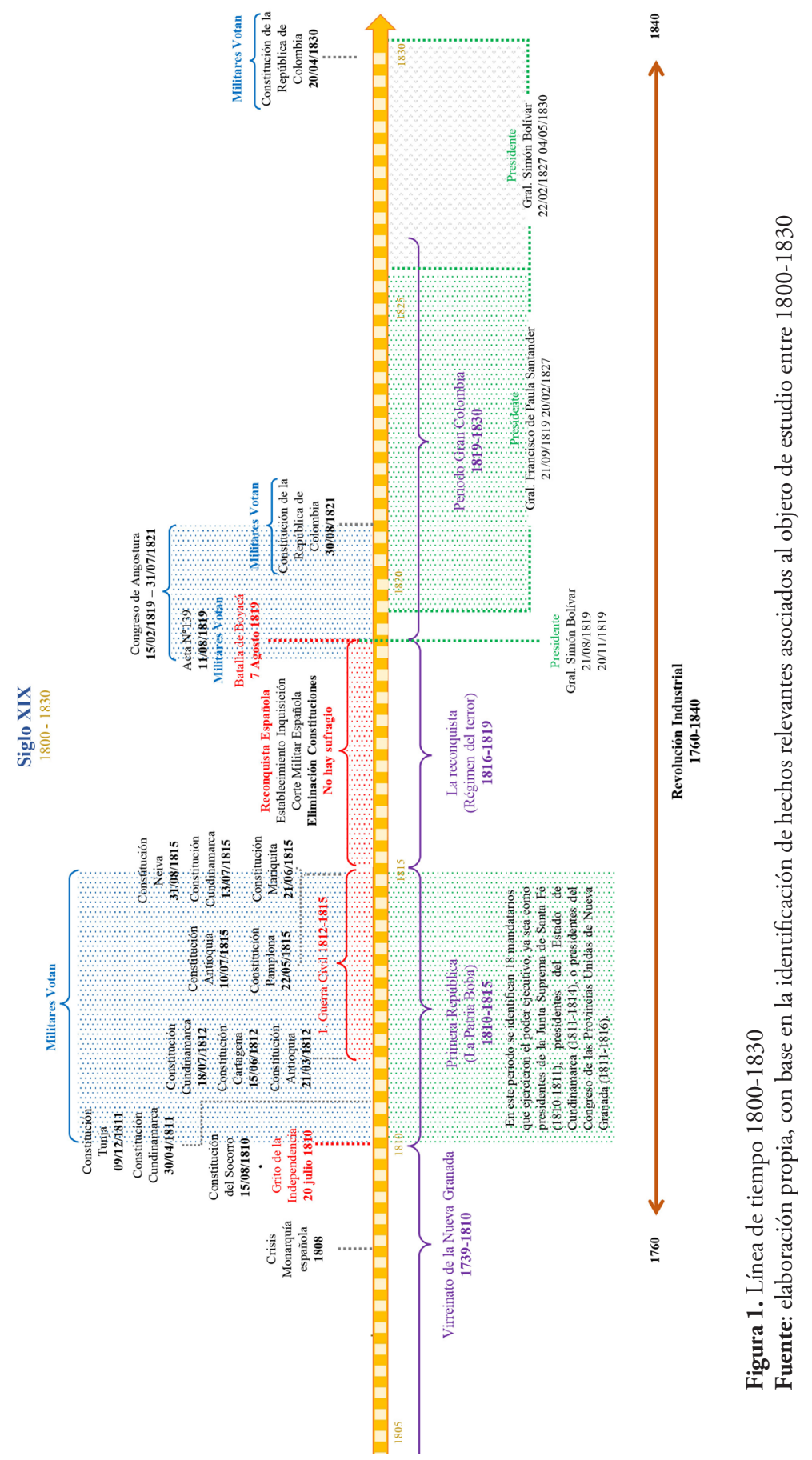




\section{Periodo de las Provincias Unidas de la Nueva Granada (La Patria Boba 1810-1816)}

Durante el periodo 1810-1815, cuando Colombia se encontraba organizada en provincias federales, se promulgaron once Constituciones en ocho provincias diferentes, estas fueron: 1. Constitución del Socorro ${ }^{7}$ (1810); 2. Constitución de Cundinamarca ${ }^{8}$ (1811); 3. Constitución de Tunja9 (1811); 4. Constitución de Antioquia ${ }^{10}$ (1811); 5. Constitución de Cartagena de Indias $^{11}$ (1811); 6. Constitución de Cundinamarca ${ }^{12}$ (1812); 7. Constitución de Mariquita $^{13}$ (1815); 8. Constitución de Antioquia ${ }^{14}$ (1815); 9. Reforma de la Constitución de Cundinamarca de $1812^{15}(1815)$; 10. Constitución de Pamplona ${ }^{16}$ (1815); y 11. Constitución de Neiva ${ }^{17}$ (1815).

Los derechos políticos de las Constituciones eran limitados, excluyentes y se encontraban asociados al derecho a elegir y ser elegido, cabe resaltar que los militares podían votar. Los parámetros de restricción estaban condicionados por tres diferentes factores:

1. Políticos, asociados al género, la edad, la nacionalidad, la vecindad, el buen proceder, entre otros.

2. Económicos, asociados al pago de impuestos y a la capacidad adquisitiva de los individuos.

3. Sociales, asociados a la utilidad social del sujeto, al desempeño de su labor dentro de la esfera social, a su autonomía e independencia de otras personas y a su capacidad cognitiva.

7 Acta de la Constitución del Estado Libre e independiente del Socorro, del 15 de agosto de 1810.

8 Constitución de Cundinamarca, del 30 de marzo de 1811, promulgada el 2 de abril de 1811 (Uribe Vargas, 1985, p. 349).

9 Constitución de la República de Tunja, del 09 de diciembre de 1811 (Uribe, 1985, p. 429).

10 Constitución del Estado de Antioquia, del 21 de marzo de 1812 y aceptada por el pueblo el 03 de mayo de 1812 (Uribe, 1985, p. 463).

11 Constitución del Estado de Cartagena de Indias, del 15 de junio de 1812 (Uribe, 1985, p. 515).

12 Constitución de la República de Cundinamarca, del 18 de julio de 1812 (Uribe, 1985, p. 581).

13 Constitución del Estado de Mariquita, del 21 de junio de 1815 (Uribe, 1985, p. 645).

14 Constitución provisional de la provincia de Antioquia, del 10 de julio de 1815 (Uribe, 1985, p. 682).

15 Plan de reforma o revisión de la Constitución de la provincia de Cundinamarca del año 1812, del 13 de julio de 1815 (Uribe, 1985, p. 719).

16 Reglamento para el Gobierno provisorio de la provincia de Pamplona, del 22 de mayo de 1815 (Uribe, 1985, p. 741).

17 Constitución del Estado libre de Neiva, del 31 de agosto de 1815 (Uribe, 1985, p. 763). 
Con relación a los derechos otorgados y los deberes exigidos a las Fuerzas Armadas en cada una las Constituciones que corresponden a este periodo, es posible evidenciar que los soldados tenían una estrecha relación con la ciudadanía y sus derechos por las siguientes consideraciones:

1. Existía un vínculo directo entre ser soldado y ser ciudadano, debido a que en todas las Constituciones de este periodo se manifestó que todo ciudadano estaba en la obligación de llevar las armas, sin distinción de clase, estado o condición; y nadie podía ser eximido del servicio militar cuando peligrara la patria.

2. En estas sociedades provinciales no todos tenían el privilegio de ser ciudadanos, por lo tanto, si se llegase a presentar una carencia de tropas a la hora de afrontar un conflicto, las constituciones ordenaban que todo hombre, sin distinción de clase, estado o condición, estaba obligado, no solo a militar, sino a vestirse, armarse y mantenerse a su costa, y el Estado cuidaría de socorrer a aquellos que indispensablemente necesitasen auxilios, si un hombre se negaba a cumplir los requisitos anteriores, perdería su condición de ciudadano, además debería salir de la provincia y en su documento de identidad se le tildaría de cobarde y vil.

3. Para que un hombre pudiese gozar plenamente de los derechos otorgados con el estatus de ciudadano, debía estar en las listas de su distrito, es decir que para poder ejercer su derecho de sufragio debía enlistarse en la Fuerza Armada para que fuese convocado a incorporación o debía pertenecer activamente a ella.

\section{Régimen del terror, la reconquista (1815-1819)}

Luego de la crisis presentada por la pérdida del trono de Fernando VII en España a manos de Napoleón, la monarquía española tardó cerca de ocho años en retomar una iniciativa que le permitiera recuperar los territorios perdidos en la Nueva Granada. Durante los años 1815 y 1819, el general Pablo Morillo comandó un Ejército expedicionario español, integrado por veteranos de la lucha contra Francia, quienes tenían como objetivo principal aplastar la revolución colonial en América. 
El general Morillo logró dominar Cartagena luego de "un sitio de ciento seis días, durante el cual los habitantes de la ciudad se vieron obligados a alimentarse con burros, ratas y bacalao rancio; centenares murieron" (Bushnell, 2014, p. 77). Luego de tomar la ciudad, Morillo estableció la inquisición y una corte militar para juzgar a los principales patriotas que fueran prisioneros, las ejecuciones contra los traidores de la Corona no se hicieron esperar y se realizaron fuera de las murallas de Cartagena.

En todo el territorio se instauró una política de terror, mediante la cual se pretendía eliminar a los líderes militares y políticos de la Patria Boba, así como a cualquier intento de insubordinación por parte de las poblaciones. En este periodo "más de 300 personas fueron ejecutadas en el país, incluidos el presidente Camilo Torres y el prominente científico criollo Francisco José de Caldas" (Bushnell, 2014, p. 78). Cabe resaltar que, durante los años del terror las constituciones que se habían generado en el periodo de la Patria Boba perdieron su fuerza, así, los derechos que habían adquirido los diferentes ciudadanos se habían perdido.

\section{Revolución por la independencia}

Las consecuencias de la independencia fueron varias: en la Nueva Granada el poder político, conformado por las élites de ascendencia criolla fueron fusilados por las tropas de Morillo; el poder económico, soportado principalmente por la agricultura, la ganadería y la minería. se vio gravemente afectado debido a que los trabajadores fueron reclutados para integrar el Ejército y el ganado fue empleado para abastecer las tropas.

La minería se vio afectada por la falta de trabajadores de aluvión, lo que significó una disminución cercana al 40\% en la producción (Ocampo, 2017, p. 104). El poder social tuvo grandes cambios en su estructura, "los esclavos que combatieron en el Ejército libertador, obtuvieron la libertad como recompensa, otros aprovecharon la confusión de la guerra para escapar" (Bushnell, 2014, p. 81), la población libre tenía la oportunidad de realizar el servicio militar y mejorar su escala social. A raíz de la independencia, los grupos dominantes comenzaron a constituirse entre criollos, mestizos y algunos afros. 
Desde el 15 de febrero de 1819 hasta el 31 de julio de 1821, se instaló en Angostura (Venezuela) un Congreso legislativo integrado por 30 diputados de provincias venezolanas elegidos desde octubre de 1818 (Hernández, 2019). Según el Acta del Congreso de Angostura No. 139, del 11 de agosto de 1819, título 3, Sección 1a: De los ciudadanos, se establecen las primeras condiciones de la ciudadanía la cual se divide en dos: la Ciudadanía activa que "goza del derecho al sufragio y ejerce por medio de él la soberanía nacional, nombrando sus representantes" (Lleras \& López, 1988); y la ciudadanía pasiva que "goza de la protección de la ley, no tiene parte en su formación, no ejerce la soberanía nacional ni goza del sufragio" (Lleras \& López, 1988).

Los requisitos para ser ciudadano activo se encuentran establecidos en el artículo No. 4 de la misma sección, entre los cuales se destacan los que señalan la necesidad de: ser nacido en territorio de la República, o ser extranjero con carta de naturaleza; tener domicilio o ser vecino de cualquier parroquia; ser casado o mayor de veintiún años; saber leer y escribir (aplica para después de 1830 y no aplica para extranjeros); tener propiedad raíz de valor de 500 pesos o tener algún grado o aprobación pública en una ciencia o arte liberal o mecánica; gozar de un grado militar, o tener un empleo o renta de 300 pesos por año (Lleras \& López, 1988).

$\mathrm{Al}$ parecer, los requisitos anteriores podrían excluir a algunos militares de la ciudadanía activa, sin embargo, en el artículo No. 7 se estipuló: "los militares, sean naturales o extranjeros, que han combatido por la libertad e independencia de la patria en la presente guerra, gozarán del derecho de ciudadanos activos, aun cuando no tengan las cualidades exigidas en los artículos cuarto, quinto y sexto, de este título" (Lleras \& López, 2019, p. 129).

En conclusión, los militares podían votar en esta época, el voto hacía parte del fuero militar gracias a sus desempeños meritorios en la campaña libertadora ${ }^{18}$. Por otra parte, la ciudadanía activa la podían perder quienes hubiesen cometido crímenes o infamias, o hubiesen vendido o comprado votos; asimismo, quienes se ausentaran del territorio de la república por más

18 Este reconocimiento político no es nuevo en la historia. Cabe recordar que en la ciudadanía ateniense los ciudadanos "Thetes" eran aquellos que no tenían ingresos suficientes para adquirir sus armas y debían embarcarse como remeros en las flotas atenienses para ir a la guerra, con la promesa de volver y obtener el derecho a participar en los asuntos públicos. 
de cuatro años consecutivos, a excepción de aquellos que lo hicieran con autorización del Gobierno; de igual manera, esta ciudadanía se podía suspender a las personas catalogadas como locos furiosos o dementes, deudores fallidos o vagos, criminales, evasores de impuestos, y los casados que no convivieran con sus esposas.

\section{Periodo de la Gran Colombia 1819-1830}

\section{Constitución de 1821}

El 30 de agosto de 1821 se redactó la primera Constitución del periodo de la Gran Colombia, en la cual se identifican dos tipos de votaciones: las parroquiales y las de provincia. Las primeras se llevaban a cabo en las asambleas parroquiales, donde se votaba por el elector o los electores, que serían quienes votarían en las elecciones de provincia. Estos votos se hacían de manera pública (no había voto secreto).

Para poder ejercer el sufragio en las parroquias se debía ser colombiano, casado o mayor de 21 años (Uribe, 1985, p. 810), saber leer y escribir (esta condición aplica para después de 1840), ser dueño de alguna propiedad con valor mínimo de 100 pesos, de no poseerla se debería ejercer algún oficio, profesión o utilidad, y no depender de otra persona en la clase de jornalero o sirviente. A su vez, se advierte que este derecho sería revocado en los casos en que la persona admitiera un empleo con otro gobierno sin autorización del Congreso colombiano, así como por sentencia a penas criminales o por compra o venta del sufragio; de igual manera, tendrían vetado el derecho los locos, furiosos, dementes, deudores fallidos, vagos, criminales o condenados que no hayan sido absueltos y los deudores públicos.

Para ser elector de provincia se debía ser sufragante parroquial, por lo tanto, todas aquellas personas vetadas del derecho al sufragio quedaban excluidas, además debían saber leer y escribir, ser mayores de 25 años y ser vecinos de alguna parroquia del Cantón donde tuviesen lugar las elecciones, tener una propiedad de un valor de 500 pesos, tener un empleo o ser dueños de bienes que produjesen una renta anual de 300 pesos, además debían profesar una ciencia o tener un grado de científico (Uribe, 1985, p. 811). 
Debido a que el Congreso de Angostura había facultado a los miembros del Ejército libertador a ejercer el sufragio, aun cuando no cumplieran con los requisitos establecidos para otros ciudadanos, los militares participaron mediante "el sufragio para elegir a los miembros del Congreso que debía redactar la primera Constitución” (Pinzón de Lewin, 1994, p. 9). "La votación fue relativamente abundante por la participación de los soldados, voluntarios extranjeros y a muchos analfabetos, algunos de los cuales eran miembros del Ejército patriota" (Bushnell, 1975, p. 29). Este acto de ampliación del sufragio determinó que la elección fuera inusualmente democrática para la época.

\section{Constitución de 1830}

El 29 de abril de 1830 se redacta una nueva Constitución que se caracterizó por exaltar los derechos políticos. En ella se estableció que todas las personas tenían igual derecho de elegir y ser elegidos para los destinos públicos si eran ciudadanos (la tabla 1) muestra una comparativa entre esta Constitución y la de 1821). Para serlo, se debía ser colombiano, casado o mayor de 21 ańos, saber leer y escribir, tener un bien raíz de 300 pesos o ejercer una profesión o industria que generase una renta anual de 150 pesos; además, no se debía depender de otra persona en la clase de jornalero o sirviente, en caso tal de ser sirviente el derecho sería suspendido, como sucedería también con los vagos, ebrios, deudores fallidos o los que tuviesen causa criminal pendiente. 
Tabla 1. Comparativo de requisitos para sufragar en las Constituciones de 1821 y 1830

\begin{tabular}{|c|c|c|c|c|}
\hline \multirow{2}{*}{$\begin{array}{c}\text { REQUISITOS } \\
\text { PARA SUFRAGAR }\end{array}$} & \multicolumn{2}{|c|}{ ELECTOR PARROQUIAL } & \multicolumn{2}{|c|}{ ELECTOR PROVINCIAL } \\
\hline & $\begin{array}{c}\text { Constitución } \\
1821\end{array}$ & $\begin{array}{c}\text { Constitución } \\
1830\end{array}$ & $\begin{array}{c}\text { Constitución } \\
1821\end{array}$ & $\begin{array}{c}\text { Constitución } \\
1830\end{array}$ \\
\hline \multirow{3}{*}{$\begin{array}{l}\text { FACTORES } \\
\text { SOCIALES: } \\
\text { utilidad, } \\
\text { autonomía, } \\
\text { capacidad }\end{array}$} & \multicolumn{2}{|c|}{ Ejercer profesión o utilidad. } & \multicolumn{2}{|c|}{ Ser sufragante parroquial } \\
\hline & \multirow{2}{*}{\multicolumn{2}{|c|}{$\begin{array}{l}\text { No depender de otra persona en } \\
\text { calidad de jornalero, doméstico o } \\
\text { sirviente. }\end{array}$}} & $\begin{array}{l}\text { Saber leer y } \\
\text { escribir }\end{array}$ & \\
\hline & & & \multicolumn{2}{|c|}{$\begin{array}{c}\text { Profesar una ciencia o tener un } \\
\text { grado de científico }\end{array}$} \\
\hline \multirow{3}{*}{$\begin{array}{l}\text { FACTORES } \\
\text { POLITICOS: } \\
\text { leyes, } \\
\text { edad nacionalidad, } \\
\text { otros }\end{array}$} & \multicolumn{2}{|c|}{ Ser colombiano } & \multirow{2}{*}{\multicolumn{2}{|c|}{$\begin{array}{l}\text { Vecino del Cantón que va a hacer } \\
\text { las elecciones. }\end{array}$}} \\
\hline & \multicolumn{2}{|c|}{ Casado } & & \\
\hline & Mayor & 21 años & Mayor & 25 años \\
\hline $\begin{array}{l}\text { FACTORES } \\
\text { ECONÓMICOS: } \\
\text { impuestos, } \\
\text { poder adquisitivo }\end{array}$ & $\begin{array}{l}\text { Propiedad de } \\
\text { valor mínimo } \\
100 \text { pesos }\end{array}$ & $\begin{array}{l}\text { Propiedad de } \\
\text { valor mínimo } \\
300 \text { pesos, o } \\
\text { tener una renta } \\
\text { anual de } 150 \\
\text { pesos }\end{array}$ & $\begin{array}{l}\text { Propiedad de } \\
\text { un valor de } \\
500 \text { pesos, o } \\
\text { tener empleo, } \\
\text { o ser dueño } \\
\text { de bienes que } \\
\text { produzcan una } \\
\text { renta anual de } \\
300 \text { pesos }\end{array}$ & $\begin{array}{l}\text { Propiedad raíz } \\
\text { valor de } 1500 \\
\text { pesos, o renta } \\
\text { anual de } 200 \\
\text { pesos de bienes } \\
\text { raíces, o sueldo } \\
\text { de } 300 \text { pesos } \\
\text { por ejercicio } \\
\text { de profesión. } \\
\text { sueldo de } 400 \\
\text { pesos }\end{array}$ \\
\hline
\end{tabular}

Fuente: elaboración propia, con base en la identificación de los requisitos para sufragar estipulados en las Constituciones de la Gran Colombia de 1821 y 1830 (Uribe, 1985)

En esta Constitución no se encuentra una sección destinada exclusivamente a lo referente a la Fuerza Armada (la tabla 2 muestra una comparativa de las causales de suspensión o pérdida del sufragio entre las Constituciones de 1821 y 1830), sin embargo, los derechos y deberes de estos se encuentran estrechamente relacionados con la ciudadanía por las siguientes consideraciones:

1. Se argumentaba que "todo colombiano tenía la obligación de estar presto en todo tiempo a servir y defender la patria, haciéndole sacri- 
ficio de sus bienes y vida si fuese necesario (Uribe, p. 581)”. Esto indica que todo colombiano podía ser un soldado en potencia si llegara a requerirlo la patria.

2. En esta Constitución se rompe el vínculo entre ciudadano y soldado, ya que para poder ejercer el voto no era una obligación estar enlistado, sin embargo, en tiempo de guerra se aplicaría el numeral anterior, ya que, para poder votar, todo hombre debía ser colombiano.

3. Se le otorgan al Congreso unas atribuciones especiales con relación a la Fuerza Armada, entre ellas: decretar la conscripción y organización de los Ejércitos, determinar su fuerza en paz y en guerra, así como determinar el tiempo que deban existir y formar las ordenanzas que debían regir las fuerzas de mar y tierra. Los miembros estas debían sujetarse a las leyes de la Constitución y acatar las leyes militares.

4. Las Fuerzas Armadas fueron creadas para defender la independencia y la libertad, mantener el orden público y hacer cumplir las leyes, no tenían derecho a deliberar y deberían ser obedientes a sus jefes y leyes; su régimen legal se daba por ordenanzas y leyes militares, y sus integrantes gozaban de todos los derechos de los ciudadanos.

Tabla 2. Comparativo suspensión o pérdida del sufragio en las Constituciones de 1821 y 1830

\begin{tabular}{|c|c|c|c|c|}
\hline \multirow{2}{*}{$\begin{array}{c}\text { REQUISITOS } \\
\text { PARA SUFRAGAR }\end{array}$} & \multicolumn{2}{|c|}{ ELECTOR PARROQUIAL } & \multicolumn{2}{|c|}{ ELECTOR PROVINCIAL } \\
\hline & $\begin{array}{c}\text { Constitución } \\
1821\end{array}$ & $\begin{array}{c}\text { Constitución } \\
1830\end{array}$ & $\begin{array}{c}\text { Constitución } \\
1821\end{array}$ & $\begin{array}{c}\text { Constitución } \\
1830\end{array}$ \\
\hline \multirow{3}{*}{$\begin{array}{l}\text { FACTORES } \\
\text { SOCIALES: } \\
\text { utilidad, } \\
\text { autonomía, } \\
\text { capacidad }\end{array}$} & \multicolumn{2}{|c|}{ Ejercer profesión o utilidad. } & \multicolumn{2}{|c|}{ Ser sufragante parroquial } \\
\hline & \multirow{2}{*}{\multicolumn{2}{|c|}{$\begin{array}{c}\text { No depender de otra persona en } \\
\text { calidad de jornalero, doméstico o } \\
\text { sirviente. }\end{array}$}} & $\begin{array}{l}\text { Saber leer y } \\
\text { escribir }\end{array}$ & \\
\hline & & & $\begin{array}{r}\text { Profesar una c } \\
\text { grado d }\end{array}$ & $\begin{array}{l}\text { cia o tener un } \\
\text { ientífico }\end{array}$ \\
\hline \multirow{3}{*}{$\begin{array}{l}\text { FACTORES } \\
\text { POLÍTICOS: } \\
\text { leyes, } \\
\text { edad nacionalidad, } \\
\text { otros }\end{array}$} & \multicolumn{2}{|c|}{ Ser colombiano } & \multirow{2}{*}{\multicolumn{2}{|c|}{$\begin{array}{l}\text { Vecino del Cantón que va a hacer } \\
\text { las elecciones. }\end{array}$}} \\
\hline & \multicolumn{2}{|c|}{ Casado } & & \\
\hline & \multicolumn{2}{|c|}{ Mayor de 21 años } & \multicolumn{2}{|c|}{ Mayor de 25 años } \\
\hline
\end{tabular}




\begin{tabular}{|c|c|c|c|c|}
\hline \multirow{2}{*}{$\begin{array}{c}\text { REQUISITOS } \\
\text { PARA SUFRAGAR }\end{array}$} & \multicolumn{2}{|c|}{ ELECTOR PARROQUIAL } & \multicolumn{2}{|c|}{ ELECTOR PROVINCIAL } \\
\hline & $\begin{array}{c}\text { Constitución } \\
1821\end{array}$ & $\begin{array}{c}\text { Constitución } \\
1830\end{array}$ & $\begin{array}{c}\text { Constitución } \\
1821\end{array}$ & $\begin{array}{c}\text { Constitución } \\
1830\end{array}$ \\
\hline $\begin{array}{l}\text { FACTORES } \\
\text { ECONÓMICOS: } \\
\text { impuestos, } \\
\text { poder adquisitivo }\end{array}$ & $\begin{array}{c}\text { Propiedad de } \\
\text { valor mínimo } \\
100 \text { pesos }\end{array}$ & $\begin{array}{l}\text { Propiedad de } \\
\text { valor mínimo } \\
300 \text { pesos, o } \\
\text { tener una renta } \\
\text { anual de } 150 \\
\text { pesos }\end{array}$ & $\begin{array}{l}\text { Propiedad de } \\
\text { un valor de } \\
500 \text { pesos, o } \\
\text { tener empleo, } \\
\text { o ser dueńo } \\
\text { de bienes que } \\
\text { produzcan una } \\
\text { renta anual de } \\
300 \text { pesos }\end{array}$ & $\begin{array}{c}\text { Propiedad raíz } \\
\text { valor de } 1500 \\
\text { pesos, o renta } \\
\text { anual de } 200 \\
\text { pesos de bienes } \\
\text { raíces, o sueldo } \\
\text { de } 300 \text { pesos } \\
\text { por ejercicio } \\
\text { de profesión. } \\
\text { sueldo de } 400 \\
\text { pesos }\end{array}$ \\
\hline
\end{tabular}

Fuente: elaboración propia, con base en la identificación de pérdida o suspensión del derecho a sufragar estipulados en las Constituciones de la Gran Colombia de 1821 y 1830 (Uribe, 1985)

\section{Periodo de la Nueva Granada 1831-1858}

Venezuela y Ecuador proclamaron su separación de La Gran Colombia, debido a esto se elabora la Constitución del Estado de la Nueva Granada, el 29 de febrero de 1832. Esta Constitución terminó con los privilegios de la clase militar haciendo de sus miembros simples ciudadanos. Esta eliminación del fuero militar provino, al parecer, de las mismas élites militares según lo manifestado por el Secretario de Estado del Despacho de Guerra en 1853:

Ningún privilegio, ninguna prerrogativa, distingue al militar granadino de sus demás compatriotas; pero el Ejército sí tiene un título de gloria cívica que no tiene ningún Ejército del mundo, y es que él pidió a la Convención del año de 1832 aboliese el fuero militar que separaba a sus individuos del resto de sus conciudadanos. (Valerio, 1853, p. 9)

Lo anterior, no representa que los militares hayan perdido el derecho a sufragar, esto se soporta en la exposición que realizó José Hilario López, secretario de Estado en el Despacho de Guerra y Marina al Congreso de la Nueva Granada en 1833, donde manifestó: 
Teniendo en consideración el ejecutivo que los individuos armados de la Nueva Granada disfrutan hoy de las mismas garantías que el resto de los ciudadanos, y que no gozan del fuero sino en campańa, y en los delitos puramente militares, y que por el hecho de pertenecer a la carrera de las armas no han perdido la cualidad de tales ciudadanos; y últimamente, que con el pre que les está señalado por la ley tienen asegurada su subsistencia sin depender de otro en calidad de sirviente o jornalero; declaró por resolución de julio del año pasado de 1832, que los individuos de tropa del Ejército pueden sufragar en las asambleas primarias siempre que tengan los requisitos exigidos por la constitución. (López, 1833, pp. 11-12)

Aquí se identifica claramente la relación existente entre el soldado y el ciudadano, debido a que el derecho a sufragar no se contempla como una adquisición por mérito puramente militar, sino que se reconoce al soldado como un sujeto de derechos ciudadanos, el cual, si cumple con los requisitos establecidos en la Constitución, tendría la facultad de votar, sin miramiento a sus rangos militares.

Asimismo, la institucionalidad se encargó de garantizar el derecho mediante la capacidad adquisitiva, ya que "el pago que recibían los soldados por su servicio aseguraba su capacidad económica para sufragar" (Pinzón de Lewin, 1994, p. 21) (ver figura 2). 


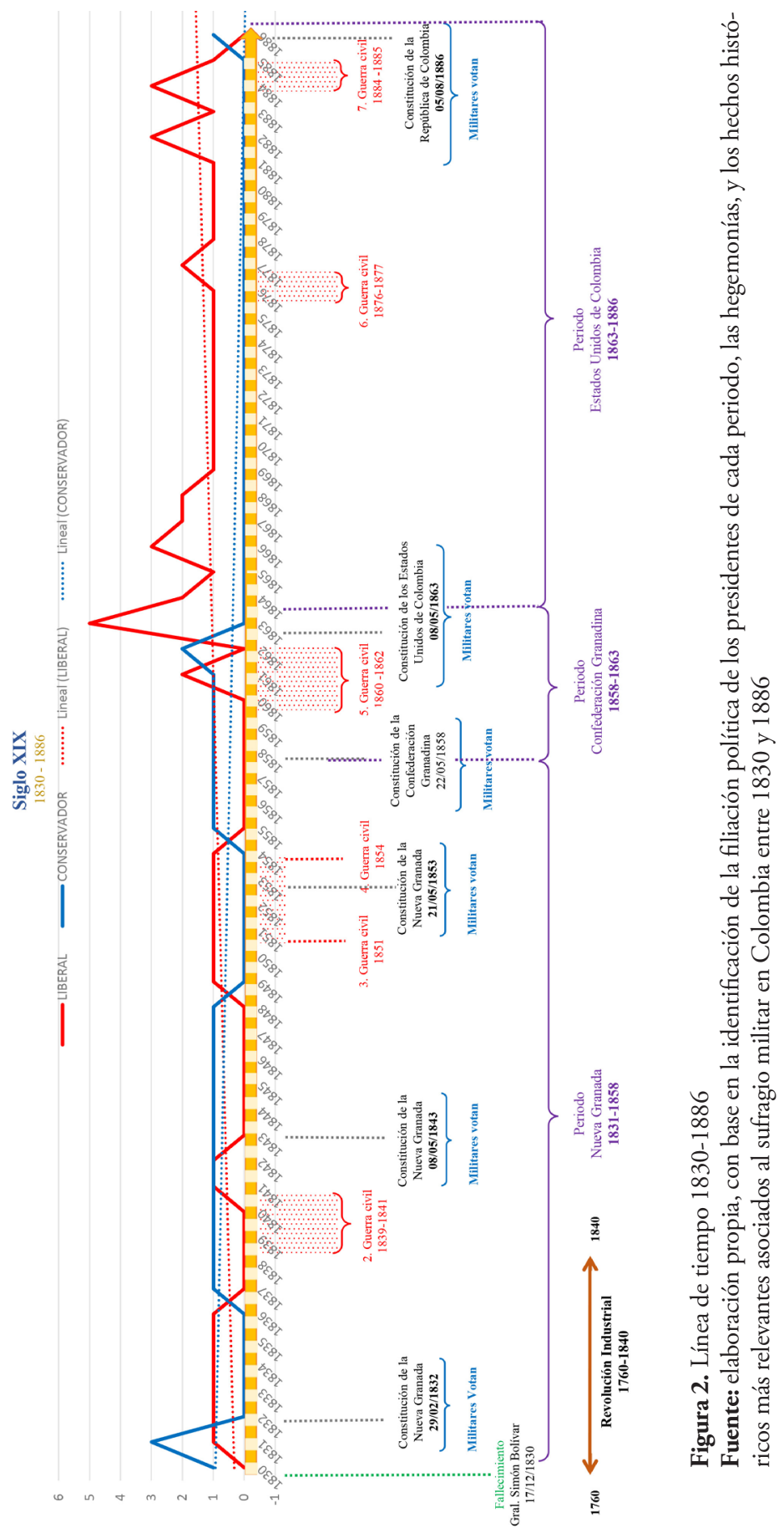




\section{Constitución del Estado de Nueva Granada 1832}

Esta Constitución establecía que para poder sufragar en las elecciones parroquiales se debía ser ciudadano granadino y ser vecino de la parroquia donde iba a sufragar, esto implicaba haber residido en esta por al menos un año antes de la elección, o manifestar ante la autoridad legal competente la intención de avecindarse en la misma. Las elecciones se realizaban cada dos años y tenían una duración de ocho días. El objetivo de estas elecciones era elegir a los electores del distrito parroquial, el cual, se encontraba en relación 1 a 1000, es decir, por cada mil habitantes que tuviese la parroquia debía haber un elector (Uribe, 1985, p. 897).

Ahora bien, para ser elector se debía ser ciudadano granadino, casado o ser mayor de 25 años, saber leer y escribir. Llama la atención que esta Constitución eliminó los requisitos habilitantes de carácter económico que, a diferencia de las Constituciones anteriores, se hallaba explícito, sin embargo, mantuvo la restricción de ser sirviente doméstico o jornalero.

De igual manera, la Constitución dedica un título para tratar lo referente a la Fuerza Armada, donde prohíbe la deliberación de sus miembros y establece el principio de la obediencia, determina que el objeto de la fuerza es defender la libertad y la independencia del Estado, mantener el orden público y proteger la Constitución y las leyes. En lo referente a los derechos de los militares, estos se encontraban relacionados con los mismos derechos otorgados a los ciudadanos, siempre y cuando cumplieran con los requisitos para ser considerado como uno de estos últimos.

\section{Constitución Política de la República de la Nueva Granada 1843}

Esta Constitución determinó que podían sufragar en las elecciones parroquiales quienes fuesen granadinos en ejercicio de sus derechos de ciudadano, mayores de 21 años que supieran leer y escribir (después de 1850), y tuviesen bienes raíces por un valor de 300 pesos o una renta anual de 150 pesos, adicional a lo anterior debían cumplir con el pago de sus impuestos.

Para ser elector provincial o cantonal, se debía ser elector parroquial, vecino del cantón que lo nombra como candidato a elector, ser mayor de 25 años y saber leer y escribir. De igual manera, eliminó las restricciones de 
profesión y utilidad impuestas en los factores sociales para sufragar, esto podría entenderse como un gesto democrático, sin embargo, dista de este carácter debido a que elevó los requisitos económicos que, para la época, no eran fáciles de cumplir. Con relación al derecho a sufragar por parte del personal militar, esta Constitución facultó a todo militar que cumpliera con los requisitos de ciudadano.

Tanto en la Constitución Política de la República de la Nueva Granada, del 20 de abril de 1843, como en la Constitución política de la Nueva Granada, del 20 de mayo de 1853, se reforzó lo plasmado en la anterior Constitución y no se modificó ningún derecho ni deber de la Fuerza Armada. Así mismo, durante el periodo de La Confederación Granadina no se decretaron cambios en la Constitución de 1858.

\section{Constitución Política de la Nueva Granada 1853}

Fue proclamada el 20 de mayo de 1853; en lo concerniente al sufragio, esta Constitución amplió la democracia debido a que eliminó en el ámbito de los factores sociales los requisitos de utilidad, autonomía y capacidad, pues ya no se requería ejercer una profesión u oficio de utilidad social, ni se establecía como obligatoria la subsistencia asegurada sin dependencia de otra persona, de igual manera, desapareció la exclusión a sufragar por ser jornalero, doméstico o sirviente.

Por otra parte, en lo referente a los factores económicos del sufragante, se estipulaba el pago de impuestos ordenados por la ley, pero se omitía el requisito de ser dueño de bienes raíces de un valor específico o la capacidad de generar una renta particularmente alta para la mayor cantidad de la población.

En el marco del sufragio se eliminaron los electores provinciales y cantonales, los ciudadanos podían sufragar por todos los niveles del gobierno: presidencia y vicepresidencia de la república, magistrados de corte suprema de justicia, procurador general de la nación, gobernador, senadores y representantes de la provincia. De igual manera, se estableció el voto directo y secreto (Uribe, 1985, p. 795), generando una ruptura en el tradicionalismo conservador, que había establecido unos requisitos excluyentes a la hora de votar. Ahora, en cambio, para sufragar solo se contemplaban factores políticos 
asociados a la ley, la edad y la nacionalidad, estas modificaciones generaron fuertes cambios en el ámbito institucional y afectaron de manera directa el poder en la época (ver tablas 3 y 4 ).

Tabla 3. Comparativo de requisitos para sufragar en la Constituciones de 1832,1843 y 1853

\begin{tabular}{|c|c|c|c|c|c|}
\hline \multirow[b]{2}{*}{$\begin{array}{c}\text { REQUISITOS } \\
\text { PARA } \\
\text { SUFRAGAR }\end{array}$} & \multicolumn{2}{|c|}{ ELECTOR PARROQUIAL } & \multicolumn{2}{|c|}{$\begin{array}{c}\text { ELECTOR } \\
\text { PROVINCIAL } \\
\text { CANTONAL }\end{array}$} & $\begin{array}{c}\text { TODO } \\
\text { TIPO DE } \\
\text { ELECCIONES }\end{array}$ \\
\hline & 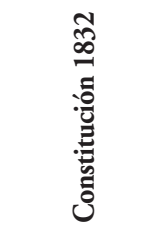 & 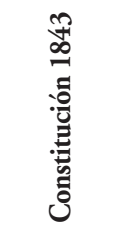 & 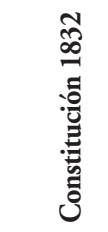 & 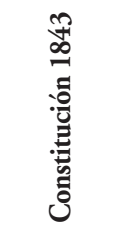 & 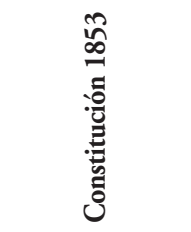 \\
\hline \multirow[b]{2}{*}{$\begin{array}{l}\text { FACTORES } \\
\text { SOCIALES: } \\
\text { utilidad, } \\
\text { autonomía, } \\
\text { capacidad }\end{array}$} & $\begin{array}{l}\text { Ejercer } \\
\text { profesión o } \\
\text { utilidad. }\end{array}$ & & \multirow{2}{*}{\multicolumn{2}{|c|}{ Saber leer y escribir. }} & \\
\hline & $\begin{array}{c}\text { Tener } \\
\text { subsistencia } \\
\text { asegurada sin } \\
\text { depender de } \\
\text { otra persona } \\
\text { en calidad } \\
\text { de jornalero, } \\
\text { doméstico o } \\
\text { sirviente. }\end{array}$ & $\begin{array}{l}\text { Saber leer } \\
\text { y escribir } \\
(+1850) .\end{array}$ & & & Omitido \\
\hline \multirow{4}{*}{$\begin{array}{l}\text { FACTORES } \\
\text { POLÍTICOS: } \\
\text { Leyes, } \\
\text { Edad Nacionalidad, } \\
\text { Otros }\end{array}$} & \multicolumn{2}{|c|}{$\begin{array}{c}\text { Ser ciudadano granadino } \\
\text { varón }\end{array}$} & \multicolumn{2}{|c|}{$\begin{array}{l}\text { Ser ciudadano granadino } \\
\text { en ejercicio de derechos. }\end{array}$} & $\begin{array}{l}\text { Ser ciudadano } \\
\text { granadino varón }\end{array}$ \\
\hline & \multirow{2}{*}{ Casado } & \multirow{3}{*}{$\begin{array}{l}\text { Mayor de } \\
21 \text { años }\end{array}$} & \multicolumn{2}{|c|}{$\begin{array}{c}\text { Vecino del Cantón que lo } \\
\text { nombra. }\end{array}$} & $\begin{array}{l}\text { Casado o que lo } \\
\text { haya sido. }\end{array}$ \\
\hline & & & Casado & & \\
\hline & $\begin{array}{l}\text { Mayor de } 21 \\
\text { años }\end{array}$ & & $\begin{array}{l}\text { Mayor d } \\
25 \text { años }\end{array}$ & 25 años. & 21 ańos. \\
\hline
\end{tabular}

Continúa tabla... 


\begin{tabular}{|c|c|c|c|c|c|}
\hline \multirow[b]{2}{*}{$\begin{array}{c}\text { REQUISITOS } \\
\text { PARA } \\
\text { SUFRAGAR }\end{array}$} & \multicolumn{2}{|c|}{ ELECTOR PARROQUIAL } & \multicolumn{2}{|c|}{$\begin{array}{c}\text { ELECTOR } \\
\text { PROVINCIAL } \\
\text { CANTONAL }\end{array}$} & \multirow{2}{*}{ 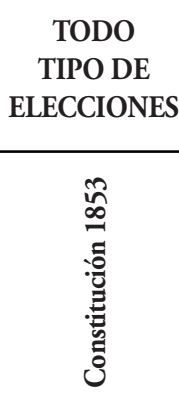 } \\
\hline & 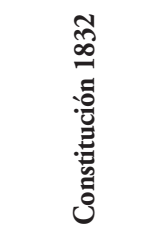 & 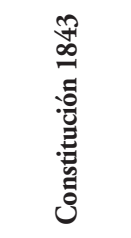 & 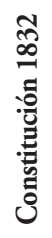 & 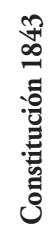 & \\
\hline \multirow[t]{2}{*}{$\begin{array}{l}\text { FACTORES } \\
\text { ECONÓMICOS } \\
\text { Impuestos, } \\
\text { Poder adquisitivo }\end{array}$} & \multirow[t]{2}{*}{$\begin{array}{c}\text { Pago de } \\
\text { impuestos }\end{array}$} & $\begin{array}{c}\text { Dueño } \\
\text { de bienes } \\
\text { raíces valor } \\
300 \text { pesos } \\
\text { o renta } \\
\text { anual de } \\
150 \text { pesos. }\end{array}$ & \multirow{2}{*}{\multicolumn{2}{|c|}{ Omitido }} & \multirow[t]{2}{*}{$\begin{array}{l}\text { Omitido } \\
\text { (de acuerdo } \\
\text { a la ley) }\end{array}$} \\
\hline & & $\begin{array}{c}\text { Pago de } \\
\text { impuestos }\end{array}$ & & & \\
\hline
\end{tabular}

Fuente: elaboración propia, con base en la identificación de los requisitos para sufragar estipulados en las Constituciones de la Gran Colombia de 1832, 1843 y 1853 (Uribe, 1985)

Tabla 4. Comparativo suspensión o pérdida del sufragio en las Constituciones de 1832, 1843 y 1853

\begin{tabular}{|c|c|c|c|}
\hline $\begin{array}{c}\text { SUSPENSIÓN } \\
\text { O PÉRDIDA } \\
\text { SUFRAGIO }\end{array}$ & $\begin{array}{c}\text { CONSTITUCIÓN } \\
1832\end{array}$ & $\begin{array}{c}\text { CONSTITUCIÓN } \\
1843\end{array}$ & $\begin{array}{c}\text { CONSTITUCIÓN } \\
1853\end{array}$ \\
\hline \multirow{3}{*}{$\begin{array}{l}\text { El derecho a } \\
\text { sufragar se pierde } \\
\text { cuando/al/por }\end{array}$} & $\begin{array}{l}\text { Se es sentenciado } \\
\text { por pena aflictiva o } \\
\text { infamante, mientras } \\
\text { no se obtenga reha- } \\
\text { bilitación. }\end{array}$ & \multirow{2}{*}{$\begin{array}{l}\text { Se es sentenciado } \\
\text { por pena aflictiva o } \\
\text { infamante, mientras } \\
\text { no se obtenga reha- } \\
\text { bilitación. }\end{array}$} & \multirow{3}{*}{$\begin{array}{l}\text { El derecho a votar } \\
\text { no se pierde ni se } \\
\text { suspende sino por } \\
\text { pena, conforme con } \\
\text { las leyes, pudiendo } \\
\text { obtenerse rehabili- } \\
\text { tación. }\end{array}$} \\
\hline & $\begin{array}{c}\text { Se vende el sufragio } \\
\text { o se compara el de } \\
\text { otro. }\end{array}$ & & \\
\hline & $\begin{array}{l}\text { Se admite tener un } \\
\text { empleo con otro } \\
\text { gobierno sin autori- } \\
\text { zación. }\end{array}$ & $\begin{array}{c}\text { Naturalizarse en país } \\
\text { extranjero. }\end{array}$ & \\
\hline
\end{tabular}

Continúa tabla... 


\begin{tabular}{|c|c|c|c|}
\hline $\begin{array}{l}\text { SUSPENSIÓN } \\
\text { O PÉRDIDA } \\
\text { SUFRAGIO }\end{array}$ & $\begin{array}{c}\text { CONSTITUCIÓN } \\
1832\end{array}$ & $\begin{array}{c}\text { CONSTITUCIÓN } \\
1843\end{array}$ & $\begin{array}{c}\text { CONSTITUCIÓN } \\
1853\end{array}$ \\
\hline \multirow{2}{*}{$\begin{array}{l}\text { El derecho a } \\
\text { sufragar se pierde } \\
\text { cuando/al/por }\end{array}$} & $\begin{array}{l}\text { Comprometerse al } \\
\text { servicio de naciones } \\
\text { enemigas. }\end{array}$ & \multirow{2}{*}{$\begin{array}{l}\text { Se vende el sufragio } \\
\text { o se compara el de } \\
\text { otro. }\end{array}$} & \multirow{9}{*}{$\begin{array}{l}\text { El derecho a votar } \\
\text { no se pierde ni se } \\
\text { suspende sino por } \\
\text { pena, conforme con } \\
\text { las leyes, pudiendo } \\
\text { obtenerse rehabili- } \\
\text { tación. }\end{array}$} \\
\hline & Fallido fraudulento. & & \\
\hline \multirow{7}{*}{$\begin{array}{l}\text { El derecho a } \\
\text { sufragar se } \\
\text { suspende cuando/ } \\
\text { al declararse/por }\end{array}$} & Enajenación mental. & \multirow[b]{2}{*}{ Enajenación mental. } & \\
\hline & $\begin{array}{l}\text { Causa criminal } \\
\text { abierta. }\end{array}$ & & \\
\hline & $\begin{array}{c}\text { Deudores a caudales } \\
\text { públicos. }\end{array}$ & \multirow{2}{*}{$\begin{array}{l}\text { Causa criminal } \\
\text { abierta }\end{array}$} & \\
\hline & $\begin{array}{l}\text { Interdicción judi- } \\
\text { cial. }\end{array}$ & & \\
\hline & $\begin{array}{l}\text { Naturalizarse en } \\
\text { país extranjero. }\end{array}$ & \multirow{2}{*}{$\begin{array}{c}\text { Deudores a caudales } \\
\text { públicos }\end{array}$} & \\
\hline & $\begin{array}{l}\text { Vagos declarados } \\
\text { tales. }\end{array}$ & & \\
\hline & $\begin{array}{l}\text { Se es sirviente o } \\
\text { jornalero. }\end{array}$ & Interdicción judicial & \\
\hline $\begin{array}{l}\text { Tienen prohibido } \\
\text { votar }\end{array}$ & $\begin{array}{l}\text { Mujeres, empleados } \\
\text { de otros gobiernos } \\
\text { sin permiso, trai- } \\
\text { dores, sentenciados, } \\
\text { fraudulentos. }\end{array}$ & $\begin{array}{l}\text { Mujeres, senten- } \\
\text { ciados por delitos } \\
\text { electorales, por } \\
\text { naturalizarse en otro } \\
\text { país. }\end{array}$ & $\begin{array}{c}\text { Por incumplimiento } \\
\text { a la ley. }\end{array}$ \\
\hline $\begin{array}{l}\text { Militares pueden } \\
\text { votar }\end{array}$ & Sí & Sí & Sí \\
\hline
\end{tabular}

Fuente: elaboración propia, con base en la identificación de pérdida o suspensión del derecho a sufragar estipulados en las Constituciones de la Nueva Granada entre 1831-1858 (Uribe, 1985) 


\section{Periodo de los Estados Unidos de Colombia (1860-1886)}

\section{Constitución de los Estados Unidos de Colombia (1863)}

Esta Constitución determinó que los derechos de elegir y ser elegido eran inherentes a los ciudadanos colombianos; para ser ciudadano, entonces, se requería ser varón mayor de 21 años y ser casado o haberlo sido; así, los militares que cumplieran con estos requisitos podían sufragar. Conocida como la Constitución de Rionegro de 1863, representó el triunfo de las libertades absolutas, la práctica de estas sumadas a los beneficios comerciales y los demás derechos otorgados llevaron a replantear las bases ideológicas del Estado; de este modo se instauró un sistema proteccionista. Esta Constitución fue revocada por la de 1886, la cual estuvo vigente hasta 1991.

\section{Periodo de la República de Colombia 1886-1930 (hecho histórico de la investigación)}

\section{Constitución de la República de Colombia (1886)}

Dentro de esta Constitución la calidad de ciudadano se otorga solo a los colombianos varones de 21 años que realicen alguna profesión, arte u oficio legal. Las formas de perder la ciudadanía determinadas por esta Carta son varias: 1) perder la nacionalidad; 2) estar al servicio de una nación enemiga; 3) pertenecer o haber pertenecido a un grupo que esté en contra de una nación amiga de Colombia; 4) haber sido condenado por pena aflictiva; 5) haber sido destituido de cargos públicos por un juicio legal; y 6) haber participado algún tipo de violencia, corrupción o falsedad en elecciones.

Con relación a los derechos civiles, políticos y sociales, esta Constitución retoma los derechos plasmados en las Constituciones anteriores (libertad, seguridad, propiedad, igualdad y educación); además, fortalece los relacionados con derecho de petición, agrupación, reunión y asociación. Esta Constitución duró un poco más de un siglo, esta continuidad y estabilidad no indican que Colombia haya vivido 105 años de rigidez constitucional, pues la Constitución de 1886 pasó por sesenta reformas. 
La Constitución de la República de Colombia del 4 de agosto de 1886 da un gran avance al intento de unificar, modificar y profesionalizar las Fuerzas Armadas. Con relación al servicio militar, determinó que todo colombiano está en la obligación de tomar las armas para defender la independencia nacional y las instituciones, para ello se estableció el servicio militar obligatorio, el cual permitiría tener a la nación un Ejército permanente con un sistema de remplazos; esta fuerza no era deliberante, no tenía derecho de reunión ni de petición si estos eran relacionados con el servicio, la moralidad o las leyes del Ejército (Uribe, 1985, p. 300).

Esta Constitución establece también el derecho de grados, honores y pensiones, así mismo les da respaldo a los tribunales militares y al código penal militar, los miembros de esta Fuerza tenían los demás derechos y libertades otorgados a los ciudadanos. Otro punto que merece atención, es que en esta Constitución se le otorga al presidente de la república el poder de disponer de la Fuerza Pública para conservar el orden nacional y restablecerlo si fuera necesario; también le permitió dirigir las operaciones de guerra como jefe de los Ejércitos de la república. En ese mismo año se creó la Escuela Militar, con el fin de profesionalizar el Ejército.

\section{República de Colombia 1886-1930}

Las luchas internas dentro de la casa liberal, las guerras civiles producto del bipartidismo político, la decadente relación con la Iglesia en el contexto de una población mayoritariamente católica y profundamente devota, el federalismo que generó el debilitamiento del orden público, la pérdida de confianza de la empresa privada por la baja demanda de productos colombianos en el mercado internacional, entre otras razones; generaron que el periodo de la hegemonía liberal del siglo XIX llegara a su fin.

El nuevo periodo de la República de Colombia se aborda desde 1886 hasta el año de 1930, cuando se presenta el hecho histórico que condujo a la supresión del voto militar. Los presidentes y su filiación o ideas políticas que gobernaron en este tiempo son mayoritariamente conservadores.

En este tiempo, la Iglesia y el clero, en su gran mayoría conservadores, manipulaban los procesos electorales mediante la aplicación de 
excomuniones, negación de sacramentos a liberales no arrepentidos, negación de acceso a los registros parroquiales para la obtención de certificados necesarios para registrar el voto, acusación de líderes liberales, el voto en masa del clero regular, las turbas que los curas organizaban en los pueblos contra los voceros liberales y el tañido de las campanas para interrumpir las reuniones liberales, las amenazas con el sufrimiento de la condenación eterna, sacar a los liberales de la casa cural. (Deas, 2002, p. 10)

Estos métodos lograron aplacar fuertemente al liberalismo debido a que la sociedad era mayoritariamente católica. Con relación a la Fuerza armada, el panorama no era diferente

se criticó al gobierno por aumentar las tropas durante el periodo de elecciones, sometiéndolas a la trashumancia electoral, desplazándolas de sitio en sitio de acuerdo con la necesidad política, y por dejar que la lealtad política que mostraban en los servicios electorales influyera en los ascensos. (Deas, 2002, p. 25)

De igual modo, era común poner las tropas a votar cuando estaban en formación, el argumento empleado por el Gobierno para justificar este acto era que así se podía mantener el orden público en el periodo electoral.

Olvidan que fue ayer no más cuando ellos mismos tuvieron que saltar por sobre las bayonetas de las guardias de pretorio, que se interponían entre la libertad de los ciudadanos y las urnas electorales, para ir a depositar en ella sus votos. No recuerdan que, en las propias calles de su ciudad, los soldados-electores que desfilaban con sus jefes a la cabeza, como un horda de vándalos, arrancaban y pisoteaban el pabellón nacional por el sólo delito de estar izado en lugar público donde se repartían las papeletas a favor de los que ellos llamaban sus enemigos políticos. Se les esfumó del recuerdo aquella escena heroica de un inminente ciudadano, el General Ospina, en un día de comicios populares, tuvo que apostrofar, en medio de la multitud pávida a los que portaban las armas de la república, para que no asesinaran a los electores que se acercaban a depositar sus votos. (Ramírez, 1931, p. 17)

Este tipo de actos conformaban el panorama de Colombia a finales del siglo XIX. Posteriormente, al finalizar la Guerra de los Mil Días, llega a la presidencia de la república el General Rafael Reyes, en 1904, quien fue el promotor de la idea de crear un Ejército profesional no partidista, para ello siguió el ejemplo del Ejército chileno para el año 1907 (ver figura 3). 
La reforma militar buscó la creación de un Ejército al servicio de la nación, se pretendía eliminar los vestigios partidistas dentro de la institución castrense, para dotarla de legitimidad nacional, para ello, se realizó una reorganización de le educación militar bajo el amparo de una misión chilena, cuyos integrantes habían aprendido de la doctrina del Imperio alemán. Para lograr eliminar la influencia conservadora en el Ejército, Reyes incentivó a que los hijos de familias liberales se formaran en la Escuela Militar, esto buscaba, a futuro, generar un balance entre los partidos políticos y las Fuerzas Armadas. Aquí cabe anotar que eliminar la influencia de un partido político en una institución jerarquizada y no deliberante, no es una tarea fácil, hay mucha resistencia al cambio y se presentan fuertes influencias que conllevan al estancamiento o al retroceso.

La reforma militar no fue del total agrado del Ejército existente [...]. Muchos ofíciales eran simplemente políticos uniformados no muy interesados en las últimas técnicas chileno-alemanas, y más que recelosos del acercamiento del presidente al enemigo liberal. Aunque ciertos oficiales continuaron con las intrigas de partido e ignorando las reglas profesionales, el Ejército en general mantuvo un registro de subordinación a la autoridad civil que solo se rompió en 1953. (Bushnell, 2014, p. 230)

Las elecciones en esta época continuaban siendo violentas, la oposición al Gobierno era diezmada, había corrupción en el conteo de votos, la Iglesia ejercía una fuerte influencia en la población y empleaba los métodos ya enunciados en periodos anteriores. La relación entre la Iglesia y el conservatismo fue el factor predominante para garantizar la hegemonía conservadora, realmente el Ejército no tenía una significativa influencia que impactara en la sociedad, como sí la tenía el catolicismo.

Como un sacerdote antioqueño aconseja a sus fieles en 1913: hombres y mujeres que me escucháis, tened presente que el parricidio, el infanticidio, el hurto, el crimen, el adulterio, el incesto, etc., son menos malos que ser liberal [...] los resultados electorales en su localidad se presentaban de la siguiente manera: católicos, 435; rebeldes contra dios y su santa iglesia, 217. (Bushnell, 2014, p. 243) 


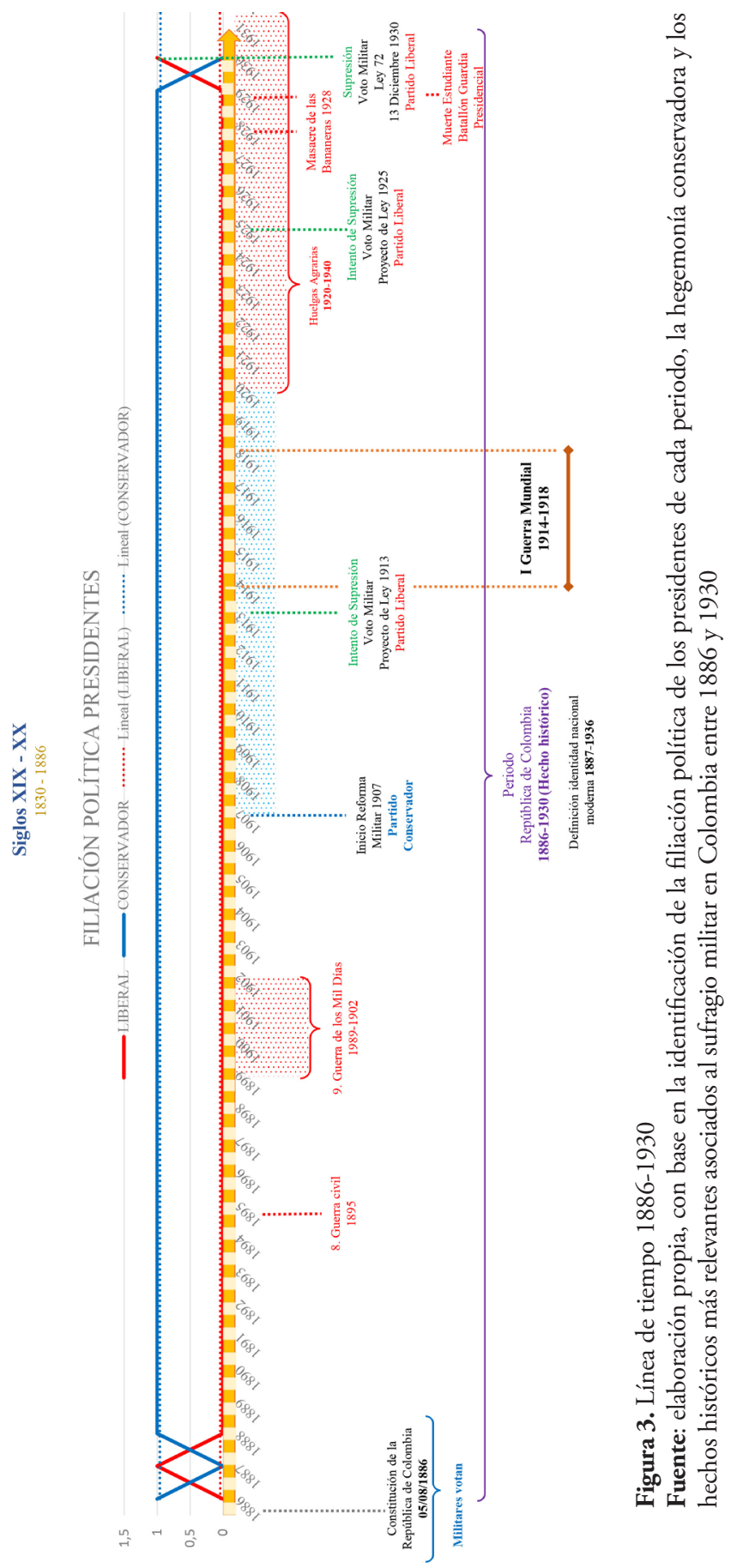




\section{Proyecto de limitación del voto militar 1913}

En 1913, el General Rafael Uribe Uribe, junto con los senadores Delgado y Díaz Granados, presentaron un proyecto de ley que pretendía reformar el concepto del sufragio en el código electoral y que replanteaba derecho al voto por parte del personal militar activo, insistiendo en el carácter no deliberante de las Fuerzas.

El derecho de tomar parte en las elecciones queda en suspenso para los miembros del Ejército, de la policía, de la gendarmería de los resguardos de aduanas y salinas y demás Fuerzas públicas armadas, mientras dichos miembros permanezcan en servicio activo. (Montoya, 1938, p. 35)

Esta iniciativa no fue aprobada por la comisión que estudió la propuesta de ley, debido a que se consideraba inconstitucional (Pinzón de Lewin, 1994, p. 66), en virtud de que todos los ciudadanos tenían derecho a votar gracias a la Constitución de 1886. Si bien dentro de la motivación del documento se hace referencia a la profesionalización y la transformación de las instituciones, el interés real de suprimir el derecho era alejar al Ejército de las luchas bipartidistas.

El General Rafael Uribe Uribe se desempeñaba como senador de la república por los departamentos de Antioquia y Caldas. Era un liberal férreo, muy arraigado y bien experimentado en la arena política. Se desempeñó como ministro plenipotenciario del cuerpo diplomático colombiano en los países de Argentina, Chile y Brasil (García, 2013, p. 17) durante los años 1905 y 1909. En sus escritos sobre la estructura del Ejército chileno se identifica una fuerte admiración por la organización de la fuerza en ese país.

Uribe Uribe quedó tan impresionado con la moderna estructura del Ejército chileno y con sus academias militares, que le rindió al presidente colombiano un detallado informe y le sugirió aprovechar ese ejemplo. El presidente acató la insinuación y con la efectiva instrucción de militares chilenos promovió la profesionalización del Ejército nacional, pionera en la modernización militar del siglo XX. (García, 2013, p. 21)

El general destacó la Escuela Militar chilena como ejemplo a seguir en Colombia. Documentó sobre su estructura, los procesos de reclutamiento, el servicio militar obligatorio, el sistema de la economía de la defensa, los salarios, el sostenimiento de la Fuerza, la tecnología armamentista; tal fue su interés 
por comprender el aparato militar de Chile que matriculó a sus hijos, Carlos y Julián Uribe, como cadetes de la Escuela Militar de Santiago, donde destacó las virtudes militares y académicas del claustro así:

No sólo una perfecta educación militar, sino todos aquellos conocimientos útiles al hombre en su lucha por la vida: matemáticas, lenguas, etc. Es opinión común la de que en los demás Institutos de Chile se instruye, pero en la Escuela Militar se educa, por cuanto física, moral e intelectualmente se forman hombres dueños de sí mismos por el saber, por el carácter y por el pundonor; aptos para el desempeńo de los más elevados puestos; elemento social culto, digno de todo respeto y consideración; y para el Ejército, un personal, vigoroso, en pleno desarrollo de todas sus facultades, y empapado en las prácticas de sus superiores, que son incansables para el trabajo, tienen por norma el cumplimiento del deber y están sometidos a una férrea disciplina [...]. (Uribe, 1955, p. 213)

Los textos sobre las instituciones militares de Chile nos comprueban que, gracias a las orientaciones que dio al gobierno nuestro, se pudo organizar un verdadero Ejército Nacional. (Morales, 1995, p. 201)

Estas opiniones permiten deducir, que la iniciativa del proyecto de ley para limitar el voto militar presentado por el general Uribe en 1913 tenía como verdadero espíritu blindar al Ejército de las luchas partidistas, apoyar el proceso de transformación hacia un verdadero Ejército nacional, quitando el interés político que pudiesen representar los votos de la Fuerza, no obstante, el legislativo determinó que esta iniciativa atentaba contra los derechos ciudadanos alcanzados en la Constitución, determinándola improcedente.

Durante los siguientes años, el Ejército incluyó dentro de sus roles y misiones la salvaguarda del orden electoral; el Ejército como institución se encargaba de garantizar las elecciones desde la perspectiva de la seguridad y el orden público, esta labor, que no pertenecía a la defensa nacional, debía ser asumida por la Policía nacional. Dicha tarea fue asignada por el Gobierno conservador y generaba inquietud en los liberales, aun cuando en las declaraciones del ministro de Guerra se manifestó que el Ejército, de manera voluntaria, se abstuvo de sufragar (Pinzón de Lewin, 1994, p. 67).

Pero la nueva fuerza se quejaba cada vez más de que participar en las elecciones, incluso guardar el orden público en época electoral, no era un asunto propio de los militares. Era malo para la disciplina, los gastos en los que se incurría disminuían los escasos fondos militares, interrumpía el entrenamiento y 
dañaba la posición y el prestigio nacional del Ejército. Los asuntos policiales debían ser manejados por la policía. (Deas, 2002, p. 26)

\section{Proyecto de limitación del voto militar (1925)}

En 1909, una nueva fuerza política surge en el escenario nacional. El partido de la Unión Republicana, conformado por liberales y conservadores, había motivado fuertemente a continuar con la reforma militar, incluyendo, por supuesto, la suspensión del voto para los miembros del Ejército y la Policía, esto lo dejó en claro en su manifiesto, publicado el 20 de marzo de 1915, donde se plantearon las bases generales de su programa político:

Conservación y perfeccionamiento del servicio militar obligatorio; continuación de la reforma militar haciéndola extensiva al Ministerio de Guerra; sostenimiento de una misión militar extranjera y envío al exterior de oficiales del Ejército Nacional, escogidos en razón de sus aptitudes. Suspensión del voto del Ejército y de la Policía. (Santos, 1915, p. 2)

El liberalismo, por su parte, también reclamaba como imperativa la aprobación de una ley de reforma electoral debido a múltiples factores, entre ellos el alto abstencionismo de la población nacional en las elecciones, el cual fue adjudicado a la desconfianza que inspiraban los sistemas electorales controlados por el Partido Conservador y por la desilusión que habían generado los elegidos (El Tiempo, 1815, p. 2).

Luego del intento de 1913 por eliminar el derecho al sufragio para los miembros activos de la Fuerza Armada, se presentó, doce años después, en 1925, un segundo intento por parte de los senadores liberales Antonio José Restrepo, el general Antonio Samper Uribe, Alejandro Galvis y José Manuel Saavedra Galindo; donde presentaron un nuevo proyecto de reforma electoral que recogía básicamente las ideas presentadas en 1913 (Pinzón de Lewin, 1994 , p. 84). "Entre sus puntos figuran el voto obligatorio, la cédula, la independencia de las corporaciones electorales y la suspensión del sufragio para las fuerzas armadas" (Montoya, 1938, p. 50).

Este proyecto cuyo "propósito era el de elevar al Ejército a fuerza de servicio y defensa de la nación sin contar con los partidos" (Montoya, 1938, p. 50), fue tildado de inconstitucional y no prosperó. En la información consultada, se puede observar que en los ideales de los partidos opuestos al Gobierno se argumentaba la imperiosa necesidad de fortalecer a las Fuerzas Armadas, separándolas 
de cualquier influencia del bipartidismo político, en especial del generado por el Partido Conservador, que mantenía el poder desde finales del siglo anterior.

\section{Supresión del voto 1930}

En el gobierno de Miguel Abadía Méndez (1926-1930) se habían presentado fuertes agitaciones en la arena política, entre ellas las protestas de las bananeras, en 1928, donde se identificó la participación conjunta del Ejército colombiano y la United Fruit Company, en la masacre de los obreros huelguistas de las bananeras (Gaitán, 1972). Las protestas sociales de las empresas públicas de Bogotá, que culminaron con la muerte del estudiante Gonzalo Bravo Pérez, el 7 de junio de 1929, a manos del Batallón Guardia Presidencial, generaron la destitución forzosa de su ministro de Guerra, Ignacio Rengifo (Latorre, 2001, p. 273).

Po otra parte, la fuerte influencia y determinación que continuaba ejerciendo la Iglesia en la selección de candidatos conservadores para los diferentes cargos políticos, entre ellos la misma presidencia de la república (Latorre, 2001, p. 276), la desconfianza popular por el proceso electoral y la continua abstención a votar, el control absoluto de los poderes del Estado por parte del Partido Conservador: "el congreso, la corte suprema de justicia, el consejo de estado, el Ejército, la policía, la burocracia” (Latorre, 2001, p. 285), motivaron a un cambio en el liderazgo político del país.

En 1930 llega a la presidencia de la república el liberal Enrique Olaya Herrera, con él se acabaron cerca de 43 años de hegemonía conservadora. Hay documentados datos curiosos sobre las elecciones de ese 9 de febrero de 1930, los cuales permiten reconstruir el contexto histórico y, en especial, la forma en que la sociedad veía a los uniformados y los asociaba con el Partido Conservador:

Un militar uniformado se presenta en una mesa, y el público lo recibe con alguna hostilidad, porque supone que sufragará por el candidato del gobierno. Se escuchan rechiflas. Entonces el militar se vuelve y dice: -Caballeros: veo que mi presencia no les agrada. $\mathrm{Y}$, sin embargo, mi voto es este [...] y muestra sus papeles con los colores del candidato liberal [...] y el público lo aclama. (Arguedas, 1989, p. 263) 
-Yo he visto repartir - me cuenta un jurado muy distinguido y de las principales familias, Enrique Nariño- a los cabos del Ejército papeletas con el nombre de Olaya Herrera. (Arguedas, 1989, p. 263)

Estos testimonios nos permiten deducir que la sociedad civil consideraba que los militares eran una identidad colectiva que estaba controlada por el Partido Conservador, esta asociación generaba repulsión por cierta parte de la sociedad, quizá por la impotencia que sentía al ver a un ciudadano portador de armas legítimas votando por el partido hegemónico. Si bien la estructura organizacional del Ejército demandaba subordinación institucional al Gobierno, en la individualidad del soldado-ciudadano no ocurría lo mismo, al parecer pudo haber sido una consecuencia del proceso de profesionalización iniciada a principios de siglo.

La Escuela Militar de Cadetes, fundada en 1907 en buena hora por el general Rafael Reyes, acababa de cumplir en 1932 sus bodas de plata. Esto significaba que de sus aulas habían salido 25 promociones de oficiales. Los salidos los primeros años de fundada ya tenían 20 años de servicio y altos grados militares; luego, tranquila y automáticamente, habían desplazado a los oficiales cuyos cargos los habían adquirido luchando por un partido.

Esto demuestra, sin lugar a dudas, que la casi totalidad de los oficiales era apolítica. El aspirante a oficial entraba a la Escuela más o menos a los 16 años, es decir cuando no pertenecía a ningún partido; en la Escuela solo recibía enseñanzas sobre patria, salía de ella alrededor de los 21 ańos y como sus compañeros tenían la misma formación militar, poco o nada le importaba la política. (Bayona, 1984, p. 47)

Por otra parte, se evidencia un caso de corrupción electoral, donde un suboficial de grado cabo fue visto repartiendo papeletas a favor del partido liberal, esto corrobora que dentro de la institución castrense no existía una homogeneización política que los obligara a votar por el Partido Conservador, incluso este acto puede representar una manifestación de rebeldía ante la misma organización.

El presidente Olaya Herrera en su discurso de posesión ante el Congreso de la República abordó diferentes temas de la agenda pública, entre ellos la masacre de las bananeras, las protestas sociales, la economía del país, y haciendo alusión al Ejército que atravesaba por una profunda crisis institucional, a raíz de los sucesos anteriormente descritos, manifestó lo siguiente: 
Los jefes, Oficiales y soldados que llevan el uniforme de la República y en cuyas manos está el pabellón de la Patria, son guardianes fieles de la Constitución y de la ley, centinelas leales del tesoro de la paz y del respeto al derecho que la república ha puesto bajo su salvaguarda. (Arciniegas, 2001, p. 300)

La supresión del voto fue motivada por el ministro de Guerra, general Agustín Morales Olaya, de filiación política conservadora y primo hermano del presidente Enrique Olaya Herrera. En consecuencia, el Congreso expidió la ley 72 de 1930 que prohibía el voto militar.

A los jefes del Ejército colombiano les corresponde el altísimo honor de haber
pedido al Congreso, por conducto del señor ministro de Guerra e invocando
el buen servicio y la moralidad de esa institución, que les suspenda el ejercicio
del sufragio mientras estén en servicio activo. Porque son dignos y porque
creen que mancharían su carrera, que es de honor y de sacrificio, mezclán-
dose en las luchas electorales, han renunciado expresamente al ejercicio de un
derecho que la Constitución no les reconoce. Esa conducta ha salvado la paz
pública y ha devuelto a la institución armada el prestigio que le arrebataron los
que la convirtieron en máquina de ganar elecciones. (Ramírez, 1931, p. 20)

La supresión del voto de los militares tenía como objetivo explícito limitar su incidencia en las luchas electorales de los partidos, buscando consolidar una conciencia suprapartidista como eje de su carácter "nacional" (Leongómez, 1987, p. 28). El argumento que se presentó en ese momento era que la Fuerza Armada estaba politizada por el Partido Conservador, es por eso que al término de la hegemonía conservadora lo primero que realizó el nuevo gobierno fue tratar de separar a las instituciones de la Fuerza Pública de los conflictos políticos; uno de los argumentos del entonces procurador general de la nación, Clodomiro Ramírez, señalaba:

Sustraer a los miembros de la institución armada de las luchas políticas, para colocarlos en el puesto que hoy ocupan los defensores de las libertades públicas de todos los colombianos; quitarles el estigma de guardias de pretorio con que los tiznaron las pasiones de bandería; devolverles una dignidad que se les quitó y que ellos necesitan para cuando llegue la hora de supremos sacrificios; mantener en toda su pureza la disciplina militar, conservando por una parte la autoridad de los jefes y por otra la fiel obediencia del soldado; conservar a Colombia la fisionomía augusta de una democracia eminentemente civil, cuando varias de sus hermanas de continente palidecen ante el brillo de los sables y sucumben entre los golpes del cuartel. (Ramírez, 1931, p. 11) 
El argumento que empleó el legislativo para aprobar la iniciativa liberal indicaba que era necesario separar la ciudadanía del derecho a sufragar, considerando que el derecho a elegir o a ser elegido es apenas un atributo de la ciudadanía, pero no constituye la ciudadanía misma. "Para elegir o ser elegido se requiere ser ciudadano, pero para ser ciudadano no se necesita el ejercicio de la facultad constitucional del voto" (Ramírez, 1931, p. 9). Otro argumento empleado fue el de la asociación entre el ejercicio de sufragar y la deliberación, los liberales manifestaron que no es posible ejercer un voto sin deliberar.

Abrid, pues, señores acusadores, los cuarteles a la propaganda eleccionaria, y habréis acabado con las bases mismas del orden público y del sistema republicano. Porque una de dos: o el soldado y el policía, respeta obedece a su jefe y vota por el candidato que le insinúa o le impone, o trabaja y sufraga por un candidato distinto, que desde afuera le recomiendan los directores políticos de su partido. (Ramírez, 1931, p. 16)

Finalmente, los militares perdieron el derecho a sufragar, debido a lo ordenado por la Ley 72 de 1930, donde su artículo No. 1 determinó que: "La Fuerza Armada no es deliberante. En consecuencia, los miembros del Ejército, de la Policía Nacional y de los cuerpos armados de carácter permanente, departamentales o municipales no pueden ejercer la función de sufragio mientras permanezcan en servicio activo" (Congreso de la República, 1930).

\section{Razones que motivaron a prescindir del derecho al sufragio a los miembros activos de Fuerzas Militares en Colombia}

Las prácticas que realizó el Ejército en favor de los partidos incluían: repartición de boletas electorales, prescripción sobre la manera de votar, insinuar o sugestionar el voto de terceros, asistir formados y armados a la mesa electoral, impedir el acceso a las urnas donde habían mayorías contrarias al partido de turno, atacar a sus enemigos políticos —en el caso de los oficiales, a quienes se les temía y se obedecía por disciplina, eran ellos quienes motivaban a la tropa sufragar por un candidato específico, movilizar urnas o destruir papeletas, entre otras cosas- (ver figura 4). En resumen, el Ejército fue el arma política del gobernante de turno. 
Nada más repugnante que ver a hombres libres y solo porque son soldados, marchar en formación, como rebaños de corderos, a dar su voto tal vez en contra de su opinión. (Pinzón de Lewin, 1994, p. 169).

Durante casi toda nuestra vida política el Ejército fue un factor electoral muy preciado, aunque la manera como el soldado hacía uso del derecho de votar siempre fue despreciable, Se llevaba a las urnas diez veces, disfrazado de ciudadano elector, y por la tarde, se le obligaba a atropellar jurados de votación y a barrer las calles a balazos. Era el árbitro siniestro de la lucha electoral. (Cano et al., 1915)

Estas malas prácticas institucionales se presentaron de manera aleatoria, pero ininterrumpidamente, desde la segunda mitad del siglo XIX, y en menor intensidad luego de la reforma militar en el siglo XX. No existía un Ejército Nacional sino unas herramientas para ganar elecciones.

No obstante, con la reforma militar iniciada por el presidente conservador Rafael Reyes, en 1904, la cual contó con la asesoría de representantes chilenos, se identificó la necesidad imperativa de apartar a los militares de la contienda bipartidista, ya que esto permitiría poder conformar un verdadero Ejército nacional. El encargado de negocios de Chile en Colombia reportó lo siguiente:

El Ejército es valeroso, y la materia prima que lo forma no puede ser mejor; pero su composición y fines patentizan una diferencia primordial: no es nacional, en el sentido de que solo sirva para defender las leyes en el interior y el honor nacional en el exterior. La culpa no es de él, sino del periodo de luchas consecutivas en que el país ha vivido. (Rodríguez, 1910)

Claramente, se evidencia desde los ojos del diplomático chileno al reportar a su país los avances de la reforma militar apoyada por militares chilenos, que el problema que retrasa el avance y profesionalización del Ejército de Colombia es la contienda bipartidista. Al respecto, es enfático sobre el tema, traza la hoja de ruta y pronostica el estado final deseado que alcanzaría el Ejército si se lograra apartarlo de los partidos.

No se trata solo de trabajos de instrucción, lo que habría sido relativamente fácil en un pueblo de índole militar como el colombiano. Había que desarraigar prácticas viciosas, sin las cuales podría, sobre todo al empezar la reforma, creerse inseguro el mismo gobierno. Era pues muy honrosa, pero muy difícil la misión encomendada a nuestros oficiales. 
Se trataba de romper hábitos que habían llegado a formar parte del modo de ser político de un país: la reforma no afectaba solo a la institución armada, sino a todo el organismo, viciado por la concepción que hasta entonces se había tenido de los fines de la fuerza armada.

Es bueno que se sepa, que, si la reforma se realiza, tendría una significación trascendental: la aparición en Sudamérica de una fuerza internacional nueva en un país rico, valeroso, de cinco millones de habitantes, y que, por su situación geográfica, es de lógica exterior que sea nuestro amigo inalterable. (Rodríguez, 1910)

Esta visión no era diferente a la que tenía don Tomás Rueda Vargas sobre el voto en el Ejército para el año de 1915, sobre ello escribió a la Convención republicana del Partido Conservador:

La reforma indicada en 1907 por la administración Reyes con el concurso de dos distinguidos oficiales chilenos, ha debido tropezar durante su camino con las naturales resistencias que le oponen los intereses creados alrededor del llamado sistema antiguo. (Rueda, 1944, p. 156)

Con esto hacía referencia a que existían facciones partidistas, e incluso miembros del Ejército, que estaban en contra de la reforma militar debido a que esta podía poner en peligro el poder político que podrían ostentar. "Mas natural es que no falten dentro de las filas mismas defensores acérrimos de los fueros de la ignorancia. Es siempre más fácil vivir sin estudiar” (Rueda, 1944, p. 156).

Por otra parte, la prensa se manifestó contra el Partido Conservador y, en una publicación de enero de 1917, le criticó fuertemente ser el artífice de la limitación evolutiva del Ejército, debido a que el Partido Conservador, siendo gobierno, no apoyaba la separación del Ejército de las contiendas políticas.

Para que el soldado sea, como es en toda nación civilizada, el depositario del honor de la patria; para que la institución militar llene cumplidamente sus fines y merezca el carińo y el respeto de todos los ciudadanos, precisa que las puertas de los cuarteles se hayan herméticamente cerradas a toda cuestión que se relacione con la política partidarista. Mientas el militar vaya a la plaza pública respirar la atmósfera caldeada de los comicios; mientras sus empatías puedan ser conquistadas por el prestigio de las candidaturas o - lo que es peor- defraudadas por la imposición; mientras las unidades de un regimiento partan el sol en las luchas democráticas, la disciplina, la homogeneidad y la nacionalización del Ejército serán un mito. (Echevarría, 1917, p. 2) 


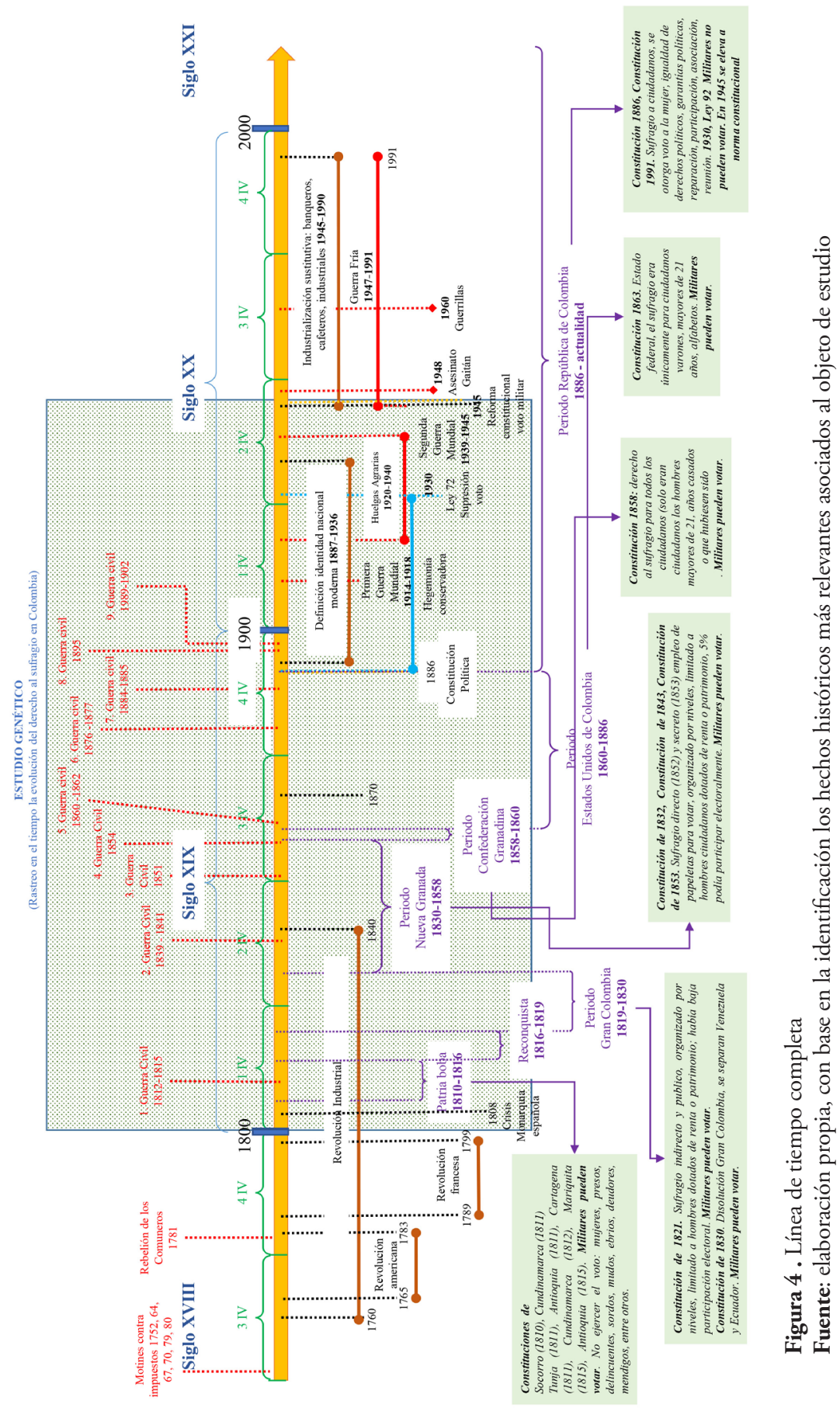




\section{Causales históricas de la restricción al sufragio}

Las causas históricas de restricción al sufragio se encuentran asociadas a tres grandes factores: sociales, económicos y políticos. A continuación, se abordará cada factor de manera individual para identificar el criterio de restricción, empleando ejemplos surgidos de la presente investigación. De igual manera, se incluirá el factor militar, con el cual se pretende evidenciar la relación que hay entre el ciudadano portador de derechos y su obligación militar (ver figura 5).

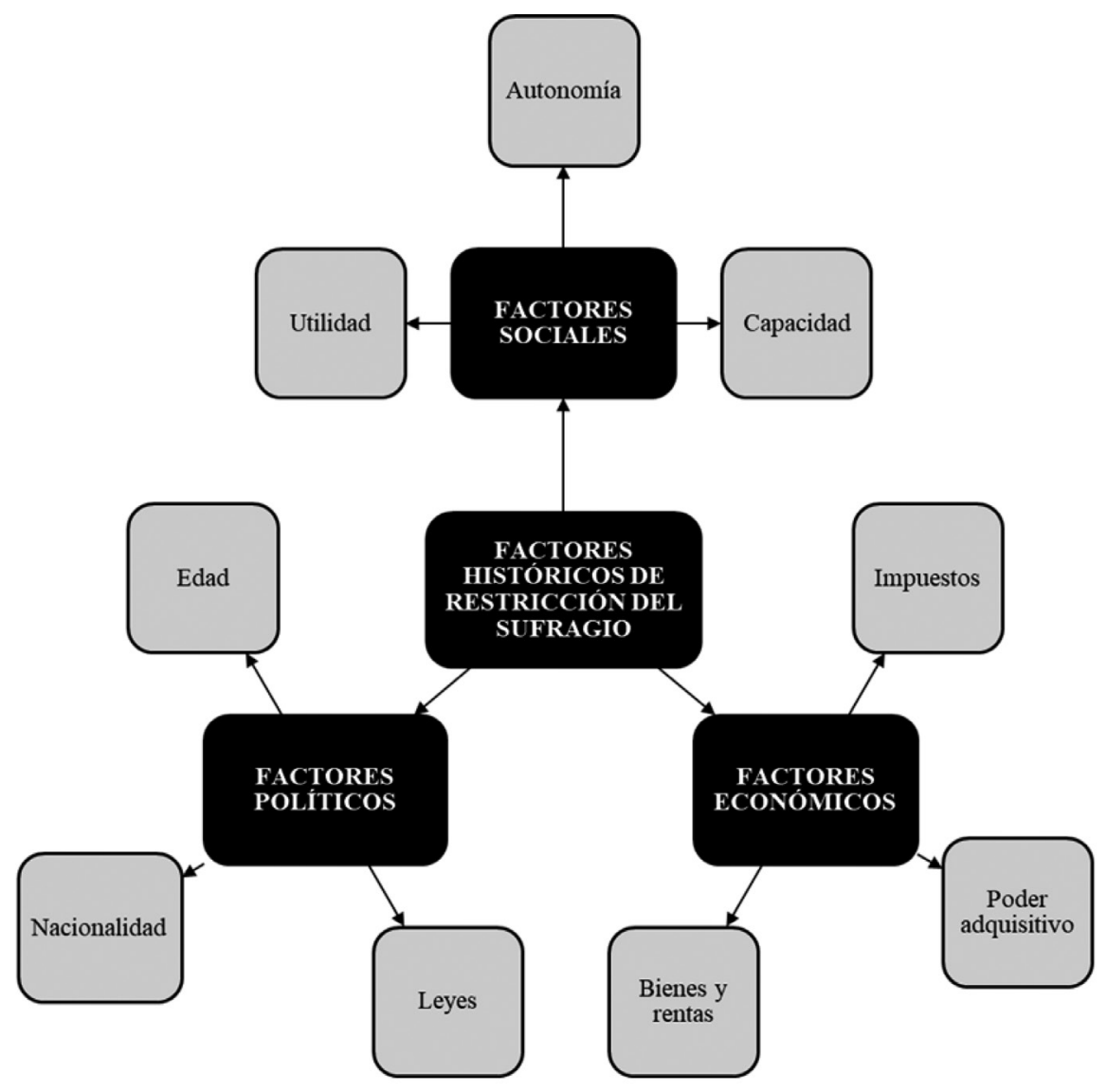

Figura 5. Causales históricas de la restricción al sufragio

Fuente: elaboración propia, con base en la identificación de factores históricos de restricción al sufragio en Colombia 


\section{Factores sociales}

El criterio de utilidad representa el interés o la ventaja que la organización política y social puede obtener, fruto del desempeño del individuo al otorgarle el derecho al voto, dicho de otra manera, la utilidad es el trabajo provechoso, por lo tanto, la organización política y social determinará que tipos de labores le serán útiles a sí misma.

En la época clásica los espartanos debían ser guerreros para poder acceder al derecho de la participación en los asuntos del gobierno, esta era su labor o su único trabajo permitido socialmente, ya que los oficios manuales estaban mal vistos en aquella época, por lo tanto, eran desempeñados por los hilotas, que no tenían derechos políticos (Heater, 2007, p. 20).

Otro ejemplo que puede ilustrar este criterio está relacionado con la ciudadanía en Grecia, donde se identificaron tres tipos de ciudadanos con diferentes funciones: los primeros son los gobernantes, quienes tienen la función de dirigir; los segundos son los soldados, quienes tienen la función de defender; y los terceros son los productores, quienes son los profesionales, hombres de negocios, comerciantes y trabajadores. De estos tres tipos de ciudadanos, con funciones sociales diferentes, se otorgaba derecho a participar solo a los dos primeros, de modo que los productores no podían participar en asuntos públicos (Heater, 2007, p. 33).

En Atenas, los thetes, aquellos ciudadanos más humildes que no tenían derecho a participar en política o asuntos de gobierno, porque no eran soldados y no podían serlo al no tener cómo comprar sus armas, debían dejar sus labores cotidianas de subsistencia e iniciar una labor útil para el Estado convirtiéndose en remeros de sus flotas de guerra, para que al volver de esta pudieran acceder a los privilegios (Benéitez, 2005, p. 17).

En la Edad Media, en Italia, quienes tenían derecho al voto eran los ciudadanos pertenecientes a algún gremio, por lo tanto, las personas que vivían en los campos quedaban excluidas de este derecho, existían dos categorías de gremios: los mayores, que eran comerciantes y que, por lo general, eran personas de la clase superior y media; y los gremios menores, que eran los artesanos y pequeños comerciantes (Heater, 2007, p. 104). 
En la era de las revoluciones, este criterio de labores útiles se difuminó; el sufragio universal pasó a limitarse con base en otro tipo de criterios, sin embargo, las limitaciones de utilidad continuaron desde el siglo XVIII hasta la época contemporánea. En Colombia, hasta la Constitución de 1843, se exigía el principio de utilidad social, por tal motivo, si el ciudadano no ejercía una profesión u oficio útil no podría votar.

El criterio de independencia (Pérez, 2002, p. 122) hace referencia a la capacidad para poder tomar decisiones sin la intervención de otra persona. Uno de los primeros teóricos que permite evidenciar la aplicación de este criterio es Aristóteles, quien al formular sus ideas de ciudadanía intuyó que este era un concepto muy amplio y difícil de definir universalmente, porque estaba compuesto por muchos factores, es por eso que formula unas categorías periféricas de ciudadanía. Aristóteles manifestaba que: "Los ciudadanos sin derecho al voto son los jóvenes o ciudadanos sin desarrollar y los ancianos o ciudadanos inhabilitados" (Heater, 2007, p. 39).

Otro ejemplo de la aplicación de este criterio, es la "restricción a la mujer a obtener el derecho de ciudadanía" (Pérez, 2002, p. 129) o el derecho a sufragar, esta limitación se debía al menguado argumento de que las mujeres solo servían para desarrollar los oficios del hogar y tener hijos, por ello no podían interferir en las decisiones importantes. Cabe también resaltar aquí a los esclavos o los carentes de libertad, los cuales eran propiedad de un amo y este podía ordenarles sufragar por alguien, sería absurdo otorgar derecho de voto a un esclavo carente de libertad, ya que no podría hacerlo bajo su criterio sino bajo el criterio de su amo, a quien le debía obediencia; este argumento aplicaba de la misma forma para los sirvientes. También se puede clasificar en este criterio a personas con carencias físicas o intelectuales, bajo el argumento de que estas dependen de otras y esto les impide elegir por sí mismas.

Todos estos requisitos habilitantes fueron incluidos en las constituciones de Colombia del siglo XIX, donde se prohibía el derecho al sufragio a "los dementes, sordomudos, locos, mentecatos, baldados o lisiados [...] [quienes] sin estos defectos son los que pueden sufragar" (Uribe, p. 358). Cabe asociar en este criterio a los militares o miembros de la Fuerza Pública, o sus equivalentes en las diferentes naciones donde son privados del derecho al sufragio, 
bajo el argumento de la carencia a deliberar o al principio de la obediencia debida. Los menores de edad, según cada criterio constitucional, también son privados del sufragio bajo el criterio de autonomía.

El criterio de capacidad, hace referencia a las exigencias mínimas de saber leer y escribir, sin embargo, este indicador se puede relacionar con otras características concernidas al razonamiento. Por ejemplo, en la época clásica, en Atenas, la participación de la sociedad en conjunto en los asuntos del Estado no era bien vista para ciertos grupos elitistas, ya que argumentaban que el pueblo era fácil de corromper y que se dejaba llevar por la demagogia o la excitación del momento y podía exigir políticas ridículas, pudiendo provocar una inestabilidad política y social debido a su superioridad numérica. En Colombia, los requisitos de alfabetización, saber leer y escribir perduraron hasta finales del siglo XX.

\section{Factores económicos}

Este criterio es un común denominador de todas las formas políticas que han existido en el mundo hasta hoy, no existe sociedad política que funcionara sin el pago de impuestos o sin sus equivalentes en cada época.

En el mundo clásico, los miembros de la casta espartiata debían realizar un arduo proceso para obtener el estatus de ciudadano y así poder participar en los asuntos de gobierno; al final de este proceso se les asignaba un comedor donde podían ser o no aceptados mediante el método explicado anteriormente. Sin embargo, si el candidato era aceptado debía pagar una cuota de avituallamiento, "cada comedor tenía alrededor de 300 miembros, cada mes se pagaba una cuota en cantidades de harina de cebada, queso, higos, vino y dinero" (Heater, 2007, p. 26). Básicamente, uno de los factores que afectaban la ciudadanía espartana era el económico, debido a que había espartiatas que no podían pagar sus cuotas mensuales y por tal razón perdían su derecho.

El sistema ateniense era similar, las cuatro clases de ciudadanos se definían de acuerdo con la cantidad de medimnos ${ }^{19}$ que poseían, el principio era

19 El "medimno" era una medida empleada para sólidos equivalente a $52 \mathrm{~kg}$; la extensión de terreno necesaria para cosechar 500 medimnos debía ser unas 16 hectáreas; para 300, unas 10 hectáreas, y para 200, de 6 a 7 hectáreas (Benéitez, 2005, p. 6) 
directamente proporcional, de tal modo que pertenecer a las clases superiores era sinónimo de tener mayor cantidad de medimnos y esto representaba mayor cantidad de derechos.

Este indicador también se presentaba en Roma, donde se empleaba un sistema de listas de ciudadanos, en las cuales se relacionaba a las personas que tenían derechos y deberes, dentro estos últimos se encontraba el de pagar los impuestos de propiedad y sucesorio (Heater, 2007, p. 64). En la Edad Media se presentó la misma situación, la Iglesia cristiana se organizó administrativamente y formó sus diócesis, en las cuales los ciudadanos debían pagar sus impuestos para poder tener sus derechos, entre ellos el de sufragio.

En los siglos XI, XII y XIII, las administraciones de los poblados o ciudades eran las encargadas de recaudar los impuestos, con el pago de ellos el ciudadano adquirirá su derecho a votar, a acceder a un cargo público a ser miembro de un jurado, etc.

Este principio económico ha trascendido desde los orígenes de las primeras organizaciones político-sociales hasta nuestros días, este indicador estuvo presente durante toda la época clásica, en la Edad Media, en la Edad Moderna, en todo el periodo de las monarquías, en la era de las revoluciones liberales, y en la época contemporánea.

En Colombia, durante los periodos correspondientes al siglo XIX y XX, se presentaron las mismas características vistas en Europa, los ciudadanos que tenían derecho al voto debían pagar impuestos, tener un salario determinado o poseer una propiedad por un valor determinado, esto se evidencia en el estudio de sus Constituciones.

\section{Factores políticos}

Este factor hace referencia a todas las restricciones de tipo político emitidas en cada sociedad. A través del tiempo, se han presentado restricciones para ejercer el sufragio por varios indicadores tales como los siguientes.

El género, las mujeres no podían votar hasta los siglos XIX y XX.

La edad: durante toda la historia de la ciudadanía se ha restringido el derecho al sufragio a los menores de cierta edad, la cual ha variado de acuerdo a la época y a las poblaciones. 
La labor: se muestra en todos los ejemplos del mundo clásico (Esparta, Atenas y Roma) y se ve en algunos países hasta nuestros días. Por ejemplo, en Italia aquellos que no pertenecieran a gremios no podían votar. En diversas partes del mundo se prohibía o restringía este derecho a los ministros sacerdotales, a los miembros del clero, a los militares, policías o sus equivalentes.

La raza: las personas que pertenecieran a una raza diferente a la de la mayoría de la población eran consideradas como otras, de afuera, extranjeras, o de la raza inferior, y eran carentes del derecho al sufragio.

La nacionalidad: este indicador se refiere a que solo podían votar quienes pertenecieran al territorio, quienes no cumplían con este requisito eran considerados extranjeros. Esta restricción aplica desde la época clásica hasta la contemporánea, fue un factor debatido por Aristóteles en la ciudadanía ateniense, en las ciudades Estado, en los imperios, en la formación de las naciones, de hecho, actualmente todo Estado aplica esta restricción para ejercer el derecho al sufragio.

Las leyes varían en cada época, en cada Estado, en cada nación, por lo tanto, para enumerar específicamente cada una de las restricciones se requeriría analizar a fondo cada Constitución u organización de la sociedad.

\section{Factores militares}

En Esparta, para ser ciudadano había que ser militar. La casta espartana, cuya base fundamental se soportaba en la supremacía militar, otorgaba el estatus de ciudadano pleno (Heater, 2007, p. 20) a aquellos soldados ciudadanos que se desempañaran en las labores militares. En Roma, el ciudadano debía atender los llamados para defender el territorio, era una obligación para ejercer plenamente su derecho de ciudadano. En la época medieval, la ciudadanía obligaba a prestar el servicio militar para poder ser ejercida de manera total.

En Colombia, durante los siglos XIX y XX, las Constituciones determinaron que el ciudadano estaba en la obligación de servir en la defensa del territorio; de igual manera, se estipuló el servicio militar como un derecho y obligación ciudadana. Un claro ejemplo de esta relación se presenta en el Acta del Congreso de Angostura, de 1819, donde se reconocieron todos los derechos plenos de la ciudadanía a los militares que participaron en la lucha por la independencia. 
No obstante, en el caso colombiano, el factor militar se vio afectado por la fuerte relación que existía entre los gobernantes de turno y la oficialidad del Ejército. El bipartidismo conformó grupos armados afines a su movimiento político, con los cuales se conformó en el siglo XIX el Ejército nacional.

El pie de fuerza del Ejército era variable y no mantenía una medida de incremento de tropas anual con relación a la población o a la extensión del territorio. En las guerras civiles del siglo XIX se presentaban aumentos exponenciales del pie de fuerza y en los años siguientes una reducción severa.

\section{Hegemonías, filiación política y Constituciones de Colombia (1800-1930)}

En cada uno de los periodos que antecedieron la República de Colombia, los partidos políticos jugaron un papel preponderante en el devenir del país. Los lineamientos políticos del gobierno de turno fueron establecidos en cada una de las Constituciones, por lo tanto, es posible identificar las principales prioridades que tenía el país en cada época. En el marco de la presente investigación, interesa identificar la filiación política predominante que motivó aquellos cambios constitucionales.

\section{Periodo de las Provincias Unidas de la Nueva Granada (Patria Boba 1810-1815)}

En este periodo el principal interés que demandaba el territorio era lograr integrar las características del ciudadano (abstracto, individual, igualitario y universal), producto de las revoluciones liberales —en especial la francesa-, con el proceso de adaptación del concepto de ciudadanía en Colombia. Estas nociones permitieron definir la ciudadanía en términos territoriales y culturales, asociados a un nivel político administrativo local, bajo el concepto de vecino (Estrada, 2011, p. 300).

En virtud de que los tomadores de decisión política de este periodo habían sido formados, en su gran mayoría, bajo la influencia directa de los pensamientos de las revoluciones liberales del siglo XVIII, se incluyeron los conceptos de libertad, igualdad, justicia, seguridad y propiedad en cada una de las Constituciones de las provincias. 
La incapacidad de ejercer una violencia legítima, que definiera la forma de gobierno en este periodo de luchas entre federalistas y centralistas, fue lo que facilitó, en gran medida, la reconquista española, debido a que los esfuerzos de las provincias estaban difuminados y no apuntaban hacia una misma dirección.

Si bien el Partido Liberal nace en Colombia en 1848, el concepto de liberalismo como idea o filiación política data de la época de la Ilustración, en el siglo XVII. Por otra parte, el Partido Conservador nace en Colombia en 1849, y sus ideas o filiación política están asociadas al proteccionismo de Estado y son antagónicas a la doctrina liberal.

En relación con el sufragio como derecho político, las Constituciones proclamaban la igualdad, libertad y equidad, pero limitaban el derecho a votar, se identifican así los primeros incidentes electorales donde estaban inmiscuidos militares asociados a los gobiernos de turno. Era un privilegio excluyente donde predominaban las restricciones sociales, políticas y económicas. En este periodo se identifican 20 presidentes, de los cuales hay 8 federalistas, cuya filiación política se asoció a las ideas liberales, y 12 centralistas, cuya filiación se asoció con las ideas conservadoras.

Debido a que Colombia se encontraba organizada en provincias federales, en este periodo se promulgaron once Constituciones en ocho provincias diferentes, estas fueron: 1) Constitución del Socorro ${ }^{20}(1810)$; 2) Constitución de Cundinamarca $^{21}$ (1811); 3) Constitución de Tunja ${ }^{22}$ (1811); 4) Constitución de Antioquia $^{23}$ (1811); 5) Constitución de Cartagena de $\operatorname{Indias}^{24}(1811)$; 6) Constitución de Cundinamarca ${ }^{25}$ (1812); 7) Constitución de Mariquita ${ }^{26}$ (1815); 8) Constitución de Antioquia ${ }^{27}$ (1815); 9) Reforma de la Constitución

20 Acta de la Constitución del Estado Libre e independiente del Socorro, del 15 de agosto de 1810.

21 Constitución de Cundinamarca, del 30 de marzo de 1811, promulgada el 2 de abril de 1811 (Uribe, 1985, p. 349).

22 Constitución de la República de Tunja, del 09 de diciembre de 1811 (Uribe, 1985, p. 429).

23 Constitución del Estado de Antioquia, del 21 de marzo de 1812 y aceptada por el pueblo el 03 de mayo de 1812 (Uribe, 1985, p. 463).

24 Constitución del Estado de Cartagena de Indias, del 15 de junio de 1812 (Uribe, 1985, p. 515).

25 Constitución de la República de Cundinamarca, del 18 de julio de 1812 (Uribe, 1985, p. 581).

26 Constitución del Estado de Mariquita, del 21 de junio de 1815 (Uribe Vargas, 1985, p. 645).

27 Constitución provisional de la provincia de Antioquia, del 10 de julio de 1815 (Uribe Vargas, 1985, p. 682). 
de Cundinamarca de $1812^{28}(1815)$; 10) Constitución de Pamplona ${ }^{29}$ (1815); y 11) Constitución de Neiva ${ }^{30}$ (1815).

Con relación a la hegemonía de la filiación política del Gobierno, no se identifica una hegemonía exclusiva, esto quiere decir que las relaciones de poder desde la perspectiva político-ideológica se encontraban balanceadas.

\section{Periodo de la Gran Colombia (1819-1830)}

Luego de la reconquista y el régimen del terror, durante los años 1815 y 1819 , el país logra su independencia, la organización del territorio cambia y pasa de los estados federales a grandes departamentos, los cuales se encontraban unidos bajo una misma y amplia organización política y territorial llamada la Gran Colombia.

En este periodo se identifican diez presidentes, de los cuales hay nueve abiertamente centralistas con una filiación política conservadora, y uno federalista con una filiación política liberal. A simple vista, se pensaría que en esos once años se presentó una hegemonía conservadora, sin embargo, es todo lo contrario, esa década estuvo marcada con ideas liberales debido a que un presidente federalista gobernó el país por casi ocho años.

Estos ideales políticos liberales se ven reflejados en la Constitución de 1821, donde los requisitos para sufragar, al menos desde el factor económico, eran menores que en la Constitución de 1830, promovida por un presidente conservador. Esta diferenciación se puede apreciar las tablas 1 y 2 del presente trabajo, donde se muestra un comparativo de los requisitos para sufragar en las constituciones de 1821 y 1830 , allí se identifica que, si bien los factores sociales y políticos tenían los mismos requisitos, en el factor económico se presentaba una restricción significativa que excluía a una gran parte de la población.

28 Plan de reforma o revisión de la Constitución de la provincia de Cundinamarca del año 1812, del 13 de julio de 1815 (Uribe, 1985, p. 719).

29 Reglamento para el Gobierno provisorio de la provincia de Pamplona, del 22 de mayo de 1815 (Uribe, 1985, p. 741).

30 Constitución del Estado libre de Neiva, del 31 de agosto de 1815 (Uribe, 1985, p. 763). 


\section{Periodo de la Nueva Granada (1831-1858) y Confederación Granadina (1858-1863)}

Este periodo marca una fuerte ruptura organizacional alcanzada en el periodo de la Gran Colombia, esto se debe principalmente a la lucha bipartidista, a la fuerte interferencia de la Iglesia en los asuntos del Estado y en gran parte a la muerte del libertador Simón Bolívar.

En este periodo los militares pierden los beneficios del fuero militar y son considerados ciudadanos normales. Pueden ejercer el derecho al voto si cumplen con los requisitos establecidos en las Constituciones de 1832, 1843 y 1853. Se identifica que la Fuerza Armada era empleada por los gobiernos de turno para manipular elecciones.

De igual manera, se identifican 15 presidentes, de los cuales 6 fueron conservadores y 9 liberales. Las Constituciones de 1832 y 1843 tienen un arraigo conservador en lo que al sufragio se refiere, hay fuertes restricciones desde la perspectiva de los factores económicos, políticos y sociales. Por el contrario, la Constitución de 1853 es eminentemente liberal y los requisitos para sufragar son mucho menores.

En este periodo los militares siguen gozando de los derechos ciudadanos. Esta información se muestra en la figura 6. Continúa el empleo del personal militar en asuntos electorales, la oficialidad se acerca a los tomadores de decisión del Gobierno (de ambos partidos) afectando la legitimidad institucional.

Con relación a las hegemonías, se presentan de manera corta las filiaciones liberales entre los periodos 1831-1836 y 1849-1854, para un total de 12 años en el poder, y las filiaciones conservadoras se presentan durante los periodos 1837-1848 y 1855-1858 para un total de 16 años en el poder.

En el caso de la Confederación Granadina, se identifican 6 presidentes, de los cuales 1 es liberal y 5 son conservadores, en este periodo el voto militar no representa un tema de interés para los tomadores de decisión, es un periodo corto donde predominan las ideas conservadoras. 

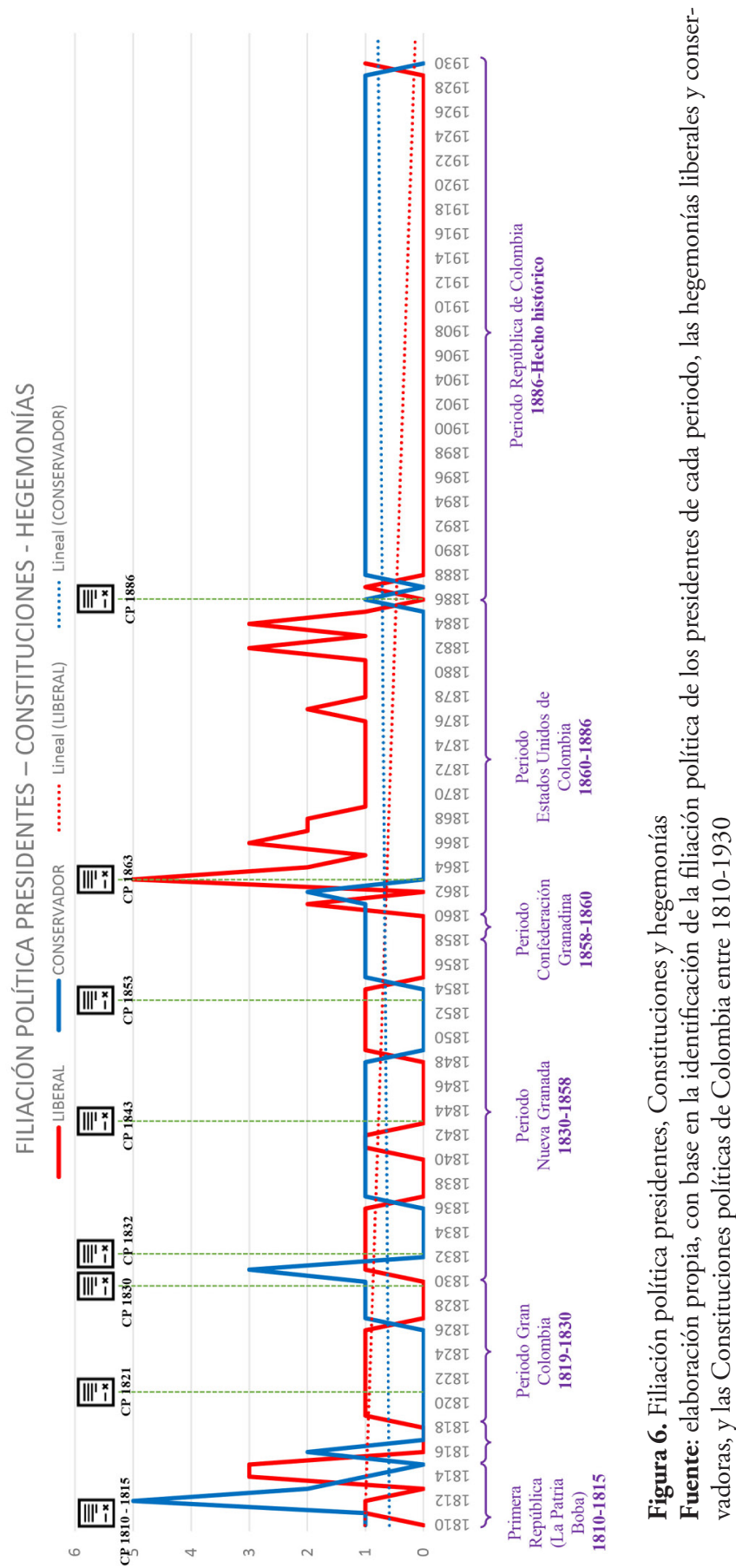


\section{Periodo de los Estados Unidos de Colombia (1860-1886)}

Este periodo representa una hegemonía exclusivamente liberal de 26 años. Hay un total de 28 presidentes, todos militantes del partido liberal. Esta hegemonía se logra gracias al uso indebido de la Fuerza Armada en asuntos electorales.

Hay manipulación de la Fuerza Militar para propender o influir en el voto de los ciudadanos. Estas malas prácticas afectaron la institucionalidad del Ejército, se realizaron las primeras protestas sociales, motivando la eliminación del sufragio militar. En este periodo se redacta la Constitución de 1863, en la cual se recogen los requisitos establecidos en las Constituciones liberales anteriores

\section{Periodo de la República de Colombia 1886-1930 (hecho histórico de la investigación)}

Este periodo representa una hegemonía conservadora de más de 30 años. Hay un total de 20 presidentes, de los cuales 19 fueron conservadores y uno liberal. El Partido Conservador realizó las mismas prácticas empleadas por los liberales en la hegemonía de los Estados Unidos de Colombia para mantenerse en el poder.

La Fuerza Militar fue empleada a favor de los conservadores, reprimiendo los ideales liberales, sumado a esto, se presenta una fuerte influencia por parte de la iglesia católica. En este periodo se lleva a cabo la reforma militar impulsada por el presidente Rafael Reyes, perteneciente al Partido Conservador, la cual plantea las bases fundamentales para la estructuración del Ejército nacional moderno.

En este periodo, el empleo de la Fuerza Militar en asuntos electorales se presenta mayoritariamente a finales del siglo XIX; luego de la reforma, la institución inició un proceso de depuración y reemplazos propio de una institución castrense, esto generó que los tomadores de decisión militar fueran formados con fundamentos democráticos y nacionalistas.

Esta reforma fue motivada por el Partido Conservador y el Ejército estaba relacionado con dicho partido; esta relación se comienza a romper a medida que evoluciona el sistema de reemplazos en la oficialidad. El Ejército era visto 
por la población como una institución conservadora, como un Ejército de los conservadores. Esto generó dos intentos de supresión del voto militar por parte del Partido Liberal, argumentando la necesidad imperativa de contar con un Ejército nacional, alejado de las contiendas políticas. Estos intentos de supresión se realizaron en 1913 y 1925.

Otro factor interesante es la pérdida de legitimidad que tuvo el Ejército, debido a su intervención en la reprensión de las protestas sociales acaecidas en este periodo, ya que, como se documentó anteriormente en este trabajo, se dieron dos grandes eventos que culminaron con la destitución del ministro de Guerra de la época.

Finalmente, en el año 1930 sube al poder un presidente liberal, Enrique Olaya Herrera, quien impulsó políticamente la supresión del voto, sin embargo, está documentado en este trabajo que la motivación para eliminar el derecho a votar provino de los mismos militares, quienes habían sido formados en el marco de la reforma militar y ahora ostentaban cargos de poder dentro de la institución castrense.

\section{Conclusiones}

Para reconstruir el contexto histórico colombiano relacionado con la ciudadanía, el sufragio y las labores militares, se realizó un análisis comparativo de once constituciones del periodo de las Provincias Unidas de la Nueva Granada (1810-1816), de las Constituciones de 1821 y 1830 del periodo de la Gran Colombia, las Constituciones de 1832, 1843 y 1853 del periodo de la Nueva Granada (1831-1858), la Constitución de 1863 del periodo de los Estados Unidos de Colombia (1860-1886), y la Constitución de 1886 del periodo de la República de Colombia.

El estudio permite aseverar que las características de restricción, así como los requisitos habilitantes para sufragar se encuentran agrupados en tres grandes factores: políticos, económicos y sociales. Es importante mencionar que en las Constituciones estudiadas se identificó un vínculo directo entre la ciudadanía y la obligación de realizar labores militares o de defensa.

De igual manera, resulta evidente que en cada periodo analizado se encuentra fuertemente marcada la influencia de las ideologías políticas que 
posteriormente conformaron los partidos tradicionales, Liberal y Conservador. En este sentido, se identificaron varios periodos hegemónicos partidistas a partir del año de 1830. En la transición entre una hegemonía y otra se presentan las guerras civiles colombianas del siglo XIX, y en el inicio de cada periodo hegemónico los gobernantes redactaban las Constituciones.

Para efectos prácticos y como aporte para análisis futuros, se diseñaron cuatro líneas de tiempo que permiten identificar los principales acontecimientos de la época, la filiación política de los presidentes, los periodos por los cuales atravesó Colombia, los conflictos bélicos, las Constituciones y la alternancia ideológica del poder ejecutivo.

En lo referente a las causas históricas de la supresión del voto militar en Colombia, se puedo concluir que el Ejército — tanto la oficialidad como la tropa- fue usado, manipulado, abusado y presionado por los grupos políticos que ostentaban el poder para ganar elecciones. "El Ejército ha sido liberal, si eran los liberales los que gobernaban; conservador si eran conservadores los dueños del poder" (Rodríguez, 1910).

Todo lo anterior permite concluir que el Ejército vinculado a las fuerzas políticas necesitaba de la eliminación del derecho al sufragio, para poder evolucionar como Ejército nacional. Ambos partidos políticos, con el contubernio de militares de alta graduación, habían explotado la subordinación de las tropas con fines electorales. En esa época, nada podía afectar más la legitimidad de la institución castrense que continuar siendo la marioneta útil de la politiquería partidista. Finalmente, estas razones fueron las que motivaron a vetar del derecho al sufragio al Ejército nacional en 1930, luego de los intentos liberales de 1913 y $1925 .{ }^{31}$

31 Conclusión obtenida en referencia al objetivo específico No. 3: analizar las causas históricas de la supresión del voto militar en Colombia. 


\section{Referencias}

Arciniegas, G. (2001). Aspectos de Olaya Herrera y su gobierno. En A. Tirado (Dir.), Nueva Historia de Colombia. Vol. 1: Colombia indígena, conquista y colonia (pp. 299-330). Planeta.

Arguedas, A. (1989). 1930: Regreso del Liberalismo al poder. En J. Melo, \& A. Valencia (Ed.), Reportaje de la historia de Colombia. 158 documentos y relatos de testigos presenciales sobre hechos ocurridos en 5 siglos (907). Planeta.

Banco Mundial. (s. f.). Personal de las fuerzas armadas, total—Colombia | Data. Banco Mundial. https://datos.bancomundial.org/indicator/MS.MIL.TOTL.P1?locations=COBayona, R. (1984). Recuerdos de un ochentón. Editorial Kelly. https://books.google.com.co/books?i$\mathrm{d}=\mathrm{MaQtAAAAIAAJ}$

Benéitez, B. (2005). La ciudadanía de la democracia ateniense. Foro Interno, 5, 37-58.

Bushnell, D. (1975). Aspectos de historia electoral colombiana del siglo XX. En D. Bushnell, Politica y Sociedad en el siglo XIX (29). Ediciones Pato Marino.

Bushnell, D. (2014). Colombia. Una nación a pesar de si misma. Nuestra historia desde los tiempos precolombinos hasta hoy. Editorial Planeta.

Cano, L., Gómez, G., \& Rueda Vargas, T. (1915). El voto en el Ejército. [Informe de la Convención Republicana de julio de 1915].

Congreso de la República. (1930). Ley 72. En desarrollo del artículo 168 de la Constitución Nacional. http://www.suin-juriscol.gov.co/viewDocument.asp?id=1621239

Deas, M. (2002). El papel de la Iglesia, el Ejército y la Policía en las elecciones colombianas entre 1850 y 1930. Boletín Cultural y Bibliográfico, 39(60), 2-29.

Echevarría, L. (1917, enero 6). Verdades que nunca se dirán demasiado. El Voto del Ejército y sus inconvenientes. El Tiempo.

El Tiempo. (1815, octubre 15). Al margen del abstencionismo. El Tiempo.

El Tiempo. (2019, septiembre 9). Voto de militares vuelve a sonar en el Congreso. El Tiempo. https://www.eltiempo.com/politica/congreso/voto-de-militares-vuelve-a-sonar-en-el-congreso-410620

Estrada, J. (2011). De vecinos a ciudadanos. Las estrategias políticas y culturales en el proceso de formación de la ciudadanía en Colombia: 1810-1860. Anuario de Historia Regional y de las Fronteras, 16(1), 295-316.

Estrada, J. (2011). La Infancia de la nación. Estrategias políticas y culturales en el proceso de formación de la ciudadanía en Colombia: 1810-1860. Clio América, 9, 63-84.

Etimologías de Chile. (s. f.). Ciudadano. Etimologías de Chile - Diccionario que explica el origen de las palabras. http://etimologias.dechile.net/?ciudadano

Gaitán, J. (1972). 1928 la Masacre en las bananeras. Ediciones Los Comuneros.

García, R. (2013). Un defensor de la alegría. Rafael Uribe Uribe (1859-1914). Editorial Universidad del Rosario. https://editorial.urosario.edu.co/pageflip/acceso-abierto/un-defensor-de-la-alegria-rafael-uribe-uribe.pdf\#page $=50 \&$ zoom $=100,0,0$

Heater, D. (2007). Ciudadanía: Una breve historia. Alianza Editorial. 
Hernández, J. (2019). ¿Qué fue el Congreso de Angostura? Radio Nacional de Colombia. https:// www.radionacional.co/noticia/congreso-angostura

Latorre, M. (2001). 1930-1934. Olaya Herrera: Un nuevo régimen. En A. Tirado (Dir.), Nueva Historia de Colombia. Vol. 1: Colombia indígena, conquista y colonia (pp. 269-303). Planeta.

Leongómez, E. (1987). La profesionalización militar en Colombia (1907-1944). Análisis Político, (1), 20-39.

Lleras, A., \& López, L. (1988). Actas del Congreso de Angostura 1819-1820. Fundación para la Conmemoración del Bicentenario del Natalicio y el Sesquicentenario de la Muerte del General Francisco de Paula Santander. http://www.bdigital.unal.edu.co/7847/1/Actas_ del_Congreso_de_Angostura_1819___1820.html

Lleras, A., \& López, L. (2019). Congreso de Angostura. Actas 1819-1820 (3ª. Ed.). Academia Colombiana de Historia.

López, J. (1833). Exposición que hace al Congreso de la Nueva Granada en 1833 el Secretario de Estado. Despacho de Guerra y Marina. http://babel.banrepcultural.org/utils/getfile/collection/p17054coll10/id/1220/filename/1221.pdf\#toolbar=1\&navpanes=1

Montoya, H. (1938). La cédula y el sufragio. Imprenta Nacional.

Morales, O. (1995). El pensador Rafael Uribe Uribe. Documenta Histórica, 45(187-188), 29-47.

Ocampo, J. (2017). Historia económica de Colombia. Fondo de Cultura Económica.

Pérez, M. (2002). Ciudadanía y Democracia (1ª. Ed.). Fundación Pablo Iglesias.

Pinzón de Lewin, P. (1994). El Ejército y las elecciones. Ensayo histórico. Cerec.

RAE. (s. f.). Ciudadano, ciudadana. RAE. https://dle.rae.es/ciudadan

Ramírez, C. (1931). Concepto del Procurador General de la Nación referente a la exequibilidad de la Ley 72 de 1930. (Voto del Ejército). Imprenta Nacional.

Rodríguez, E. (1910, abril 29). El rojo y el godo: los machetes formidables; Ejércitos de partido. Gaceta Republicana, No. 233.

Rueda, T. (1944). El Ejército nacional (Vol. 1). Librería colombiana, Camacho Roldan \& Cía. Ltda.

Sabato, H. (1999). Ciudadanía Politica y formación de las naciones. Perspectivas históricas de América Latina (1ª. Ed.). Fondo de Cultura Económica.

Santos, E. (1915, marzo 20). Manifiesto republicano. El Tiempo.

Uribe, D. (1985). Las Constituciones de Colombia Vol. 2. Ediciones cultura hispánica.

Uribe, D. (1985). Las Constituciones de Colombia Vol. 3. Ediciones cultura hispánica.

Uribe, R. (1955). Por la América del Sur. Editorial Kelly. https://books.google.com.co/books?i$\mathrm{d}=5 \mathrm{kozAQAAIAAJ}$

Valerio, B. (1853). Informe del Secretario de Estado del Despacho de Guerra de la Nueva Granada al Congreso Constitucional de 1853. Imprenta del Neo Granadino. http://babel.banrepcultural.org/cdm/ref/collection/p17054coll10/id/2340 